Gazi University
Journal of Science
http://dergipark.gov.tr/gujs

\title{
Computation of Critical Path Probabilities by Modified PERT
}

\author{
Onder Halis BETTEMIR* \\ Department of Civil Engineering, Inonu University, Malatya, Turkey
}

\author{
Highlights \\ - New fast algorithm for the computation of probability of being critical path. \\ - Comparison of PERT, Modified PERT and Monte Carlo Simulation. \\ - Effects of path elimination. \\ - Computation of the effect of step size on the project duration and uncertainty. \\ - Improvement of Modified PERT.
}

\begin{tabular}{l} 
Article Info \\
\hline \\
Received: $27 / 08 / 2019$ \\
Accepted: 09/04/2020 \\
Keywords \\
\hline PERT \\
Modified PERT \\
Monte Carlo simulation \\
Uncertainty analysis
\end{tabular}

\section{INTRODUCTION}

Duration estimations may deviate because of the external factors such as weather conditions, performance of suppliers, and failure of on-time progress payments. Besides the external factors; internal factors such as performance of project team, rework, and other issues effects the duration of construction. Duration of construction has significant importance for the contractors because the indirect cost is correlated with the construction period. In addition to this, liquidated damages may be faced if the project is completed after the deadline. If the construction duration is estimated too long to be on the safe side, cost estimations can be biased and the construction job may be missed because of too high tender price. Estimated duration includes certain amount of uncertainty, which can be defined as risk. Factors affecting the completion time of an activity are listed as learning curve, weather conditions, space congestion, absenteeism of workers, regulatory requirements, design changes and rework, economic activity level, labor unrest, crew interfacing, project complexity, ineffective supervision and consultant, legal and union problems, as well as transportation schedule. Each factor contributes to the uncertainty of the duration estimation of the activity [1].

The uncertainty of an output can be predicted by Variance Propagation Law (VPL). However, VPL cannot be directly adopted for the estimation of the uncertainty of the duration of a project since computation of 
project completion time is not a continuous function. Program Evaluation and Review Technique (PERT) is developed by U.S. Navy Special Projects Office in 1957 by neglecting the effects of shorter paths [2]. PERT assumes that the activities of the project as subjected to Beta Distribution therefore; Malcolm et al. proposed Equation (1) and Equation (2) for the computation of mean and variance of the duration of the activities respectively

$$
\begin{aligned}
& t_{e}=\frac{1}{6}[a+4 m+b], \\
& \sigma^{2}\left(t_{e}\right)=\frac{1}{6}[b-a]^{2} .
\end{aligned}
$$

Computations were made mainly by hand when PERT was developed. Therefore, computational demand of PERT was minimized as much as possible. As a result, PERT contains many assumptions to simplify the computations. Uncertainty is computed by considering only the critical path and the effects of remaining paths are neglected. The simplifications reduce not only the computational demand but also robustness of the results. Consequently, PERT is modified by researchers to improve the correctness of the results. Fulkerson computed the expected computation duration of the network for discrete activity durations. Expected project completion time is estimated by considering the path combinations obtained by equal probability of activity durations. Three case problems are solved and longer completion time is obtained by the proposed method for all of the case problems [3]. This algorithm is later modified and computational demand is reduced [4].

Sculli implemented network reduction technique by adding dummy activities and nodes so that at most two activities can end at one node [5]. The reduction made utilization of variance propagation law possible for the computation of mean and variance of the project duration. However, project reduction is made by human intervention which prevents full computerized solutions.

Robillard and Trahan estimated the project completion time without examining all of the sub-paths of the network by assuming that the activity durations are independent variables [6]. The algorithm is improved by a lower-bound approximation method. Upper-bound for the project completion is estimated by considering the lower-bound and the sub-paths [7]. Ang computed the probabilities of finishing the project for predefined durations [8]. The computed probability values are used as weighting constants and the weighted average of the completion duration is used as the estimated project completion time. Similarly uncertainty of the project completion time is also computed by using weights and the estimated project completion time. Modified PERT gives more accurate duration and uncertainty estimation than PERT. Before the development of the Monte Carlo method, risk of the construction duration is represented by variance and risk management was mainly concentrated on reducing the variance [9].

Uncertainty of project duration can also be estimated by Monte Carlo Simulation (MCS). This method estimates the uncertainty of an outcome by simulating the process many times by randomly generated numbers [10]. MCS requires important amount of computation, but implementation of the method is easy. Therefore, it is adopted by many researchers. Monte Carlo Simulation is implemented for the evaluation of the minimum usage guarantee provided by the governments for Build-Operate-Transfer projects [11]. Unified scheduling method (USM) is developed to estimate uncertainty of duration and cost by fusing the probabilistic and deterministic scheduling [12]. Graphical evaluation and review technique (GERT) is recommended because of its capability of addressing probability branches and loops [13]. In this method serial and parallel activities are joined and equivalent uncertainty of the representative activity is computed by variance propagation law. Completion time of a product development process is analyzed and probability distribution is obtained. Implementation of this technique requires human intervention because of activity join operations.

Van Slyke estimated the effects of noncritical paths on the estimated project duration by MCS [14]. Burt and Garman adopted antithetic variates, stratified sampling, control variates, regression and conditioned sampling techniques to reduce the computational demand [15]. Sigal estimated the probability of a path 
being critical by MCS and introduced criticality index [16]. Dodin and Elmaghraby reduced the number of paths of a network by network reduction and computed the criticality index by backward pass computation [17]. MCS is also implemented to model risks related with construction cost and duration. A bridge construction in Pakistan is used for the case study [18]. A model is developed between the risk factors that lead to variations in activity durations and the variations of the activity durations. Based on the developed model MCS is conducted [19]. Stochastic Project Scheduling Simulation (SPSS) software is developed to evaluate the probability of a specific project completion time [20]. The user defines the probability distributions of the activity durations and the software provides the probability of the specific project completion duration by MCS. Project completion time estimations are improved by integrating the Critical Path Method, PERT and discrete event simulation [21]. Dijkstra shortest path algorithm is modified and longest and second longest paths of the project are obtained. The provided paths are utilized for superposition of the paths to model the stochastic nature of the duration of the paths [22]. Modified Stochastic Assignment Model (MSAM) for the prediction of project duration is developed [23]. The method gives similar results with MCS with less computation. However, the developed method does not give information about the probabilities of the paths being critical path.

PERT, probabilistic network evaluation technique (PNET), narrow reliability bounds (NRB), MCS, and simplified MCS (SMCS) is compared [24]. Comparison reveals that PERT is the easiest method to implement while MCS and SMCS presents pessimistic results. Detailed information can be found in the research article for the implementation of the stochastic methods. MCS and PNET is implemented by considering the time and cost uncertainties on a 3-span bridge construction [25]. Moreover, probability of completing a project at a specific cost and probabilistic cash flow diagrams are prepared as well as, probabilities of the activities being critical or not are computed at the end of the analysis.

MacCrimmon and Ryavee examined the assumptions of PERT and revealed that due to beta distribution assumption, activity durations and standard deviations can be computed 33\% and $17 \%$ wrong respectively. It is proved that the activity durations can be false as much as $\frac{1}{60}\left[\frac{a+4 m+2 b}{b-a}\right]$ while the standard duration can be false as much as $\frac{1}{30}\left[\frac{b+a}{b-a}\right]$ [26]. Moder et al. compute activity duration and its variance as given in Equations (3) and (4) respectively to reduce the effects of improper distribution [27]

$t_{e}=\frac{1}{6}[a+4 m+b]$

$\sigma^{2}\left(t_{e}\right)=\frac{1}{3.2}[b-a]^{2}$.

Van Slyke notes that if the project duration is required to be correct within X\% of the project duration with 0.95 confidence, than minimum number of samples of MCS should have is obtained by Equation (5)

$N=\left[\frac{1.96 * 100}{2 X}\right]^{2}$.

If the variance is required to be correct within $X \%$ with 0.95 confidence, number of samples of MCS should have is computed by Equation (6) which is solved iteratively

$1.96=\frac{1+\frac{X * N}{100}}{\sqrt{2 N-2}}$.

Literature review shows that MCS successfully estimates the uncertainty of project duration and provides the probabilities of the critical paths. However, MCS requires many schedule evaluations and requires important amount of computation, which may end up with exorbitant computational demand during an iterative optimization process. For this reason, MCS is not suitable for stochastic optimization if critical paths are not constant such as time cost trade-off or multi-mode resource constrained project scheduling problems. 
Both PERT and Modified PERT methods provide mean duration and its variance for a network. However, neither method provides the probability of the paths being critical path. PERT assumes that the longest path is the critical path with $100 \%$ probability and the probability of the remaining paths being critical path is $0 \%$, which cannot be the case. Literature review reveals that Monte Carlo simulation based methods provide probabilities of activities being critical but the computational demand of this method is significantly high. Stochastic optimization on project planning is becoming widespread because construction cost and duration estimations contain uncertainty. Throughout a stochastic optimization process such as stochastic solution of time cost trade-off problem durations and uncertainties of paths are not constant as construction modes of the activities are shifted. This requires re-estimation of the probabilities of the paths being critical path.

The aforementioned deficiencies of the current methods show that there is a need for fast and robust algorithm for the prediction of the probabilities of the paths being critical path. In this study, modified PERT is improved and the algorithm became capable to compute the probabilities of the paths being critical with less computational demand than MCS. The modification involves computation of combinations of probability events formed by considering the state of the paths being complete or incomplete. Each probability event is examined and probability of the paths being critical path is computed by adding of the probabilities of the events where the considered path is critical path. This improvement is the contribution of this study.

In the second section the improvement of Modified PERT is explained in detail, third chapter presents the solutions of the five case study problems, discussion of the results and conclusion are given in the fourth chapter.

\section{METHODOLOGY}

In this study the Modified PERT (Ang's PERT) is improved and the method became capable of computing the probability of a path being critical path. In this section effects of interactions between the paths are explained. Moreover, systematic computation of distinct events formed by the combinations of the critical and noncritical paths is explained in the second subchapter. Finally, probability computation of a path being critical path is illustrated.

\subsection{Interactions between the paths}

Probability of finishing a project within certain duration is computed by Modified PERT. Finishing the project means that all of the paths are finished within the certain duration. Probabilities of finishing the paths exactly at the examined time are computed and the probabilities of finishing the paths are multiplied to compute the probability of finishing the network. This approach gives the probability of finishing the project at a certain time but does not give any information about which paths are critical or not. In order to provide information about the paths being critical or not, probabilities of finishing the paths should be computed. Complexity of this computation depends on the number of paths of the project.

For a network consisting of two paths (A and B), completion of the network requires paths $\mathrm{A}$ and $\mathrm{B}$ to be completed. Being critical path necessitates that the float duration should be zero. If the path is finished before the examined time, the path is noncritical. The path is critical if its duration is equal to the examined time. The possibilities of the network consisting of two paths are given as Venn diagram in Figure 1.

In Figure 1 set A1 represents that path $\mathrm{A}$ is critical for a given project completion time $\mathrm{X}$, and set $\mathrm{B} 1$ represents that path $B$ is critical for a given project completion time. $\mathrm{P}(\mathrm{A}=\mathrm{X})$ represents the probability of path $A$ is completed exactly at the $X^{\text {th }}$ day, $P(B=X)$ represents the probability of path $B$ is completed exactly at the $\mathrm{X}^{\text {th }}$ day. Similarly, $\mathrm{P}(\mathrm{A}<\mathrm{X})$ and $\mathrm{P}(\mathrm{B}<\mathrm{X})$ represent probability of path $\mathrm{A}$ and path $\mathrm{B}$ are completed earlier than the $\mathrm{X}^{\text {th }}$ day. 


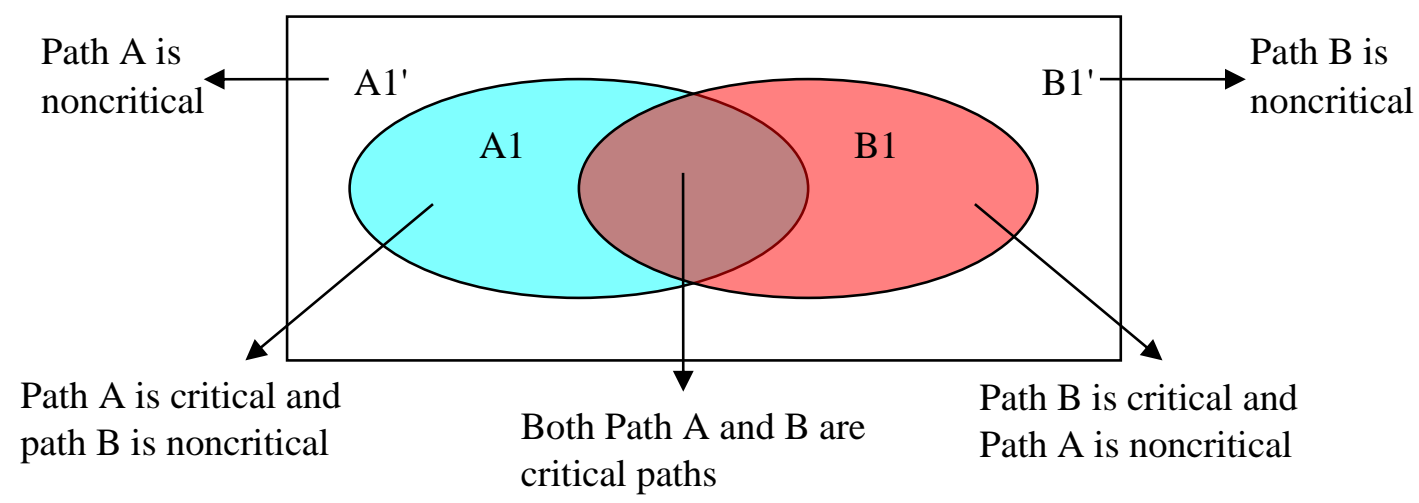

Figure 1. Possible events are shown by shaded areas in case of two paths

If there are two paths in a network, the critical path or paths can be consists of only path A, only path B and both paths $\mathrm{A}$ and $\mathrm{B}$. Three distinct events can be defined. If the critical path is only path $\mathrm{A}$, then event $\mathrm{E} 1$ states that path $\mathrm{A}$ is critical and path $\mathrm{B}$ is noncritical, whose probability is computed by $P(A=X) * P(B<X)$. Similarly if the critical path is only path $B$, then event E2 states that path A is noncritical and path $B$ is critical whose probability is computed by $\mathrm{P}(\mathrm{B}=\mathrm{X}) * \mathrm{P}(\mathrm{A}<\mathrm{X})$. The last event $\mathrm{E} 3$ states that both paths are critical whose probability of this event is computed by $\mathrm{P}(\mathrm{A}=\mathrm{X}) * \mathrm{P}(\mathrm{B}=\mathrm{X})$. Probability of path $\mathrm{A}$ being critical path will be equal to summation of the probability of the events in which path A is critical path. These events are E1 and E3, so the aforementioned probability will be equal to $P(A=X) * P(B<X)+P(A=X)$ $* P(B=X)$. Similarly probability of path B being critical path will be equal to $P(B=X) * P(A<X)+P(A=X)$ $* P(B=X)$.

Figure 2 represents the possible events of a network which consists of three paths which are represented as $\mathrm{A}, \mathrm{B}$, and C. Sets A1, B1, and C1 define the events where the paths A, B, and, C are critical paths respectively. Similarly, sets A1', B1', and $\mathrm{C} 1$ ' define the events in which paths $\mathrm{A}, \mathrm{B}$, and $\mathrm{C}$ are not the critical paths respectively. Venn diagram of the 3-path case is shown in Figure 2.

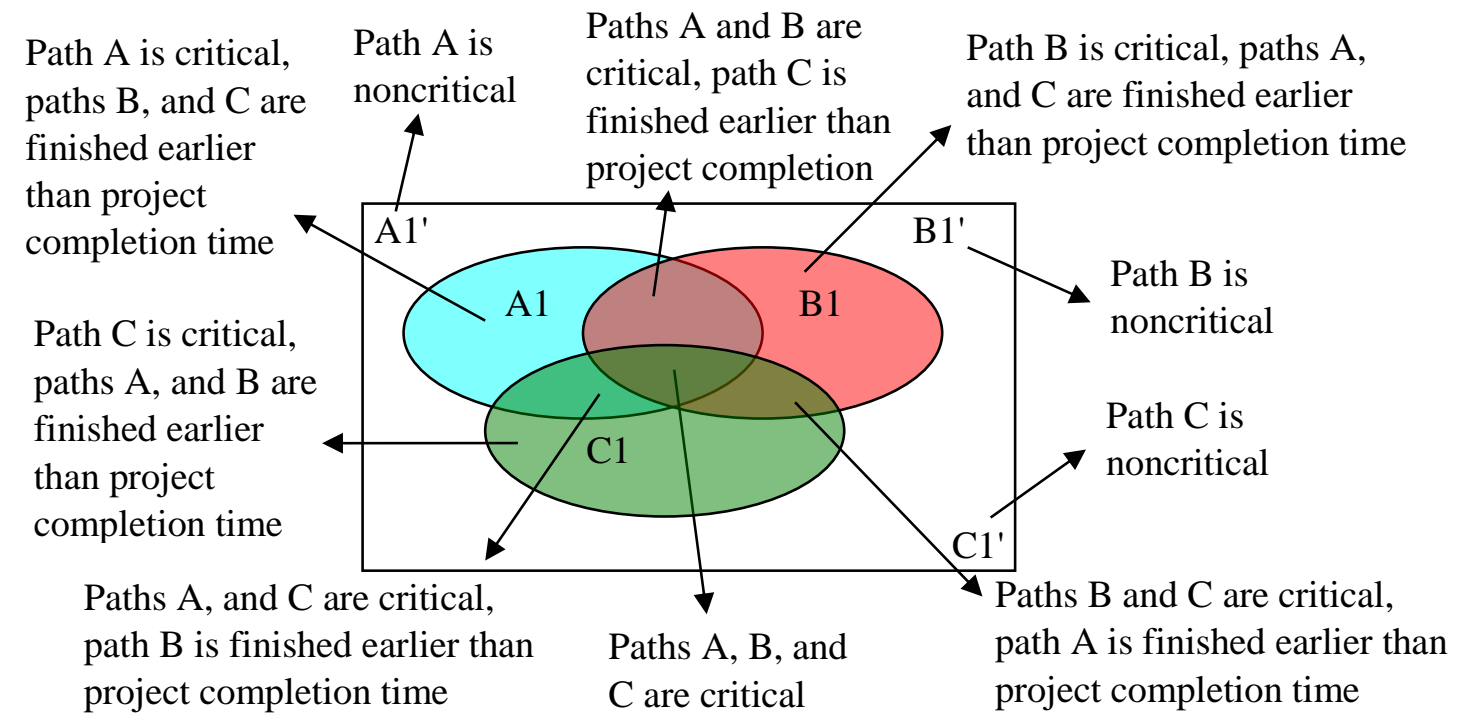

Figure 2. Possibilities of critical paths if the network has three paths

Seven different events occur for a network, which consists of three paths. The events and how their probabilities are computed are listed in Table 1. 
Table 1. Possible events for the 3-path network

\begin{tabular}{|l|l|l|l|}
\hline Events & Critical Paths & Noncritical Paths & Probability \\
\hline E1 & A, B, C & - & $\mathrm{P}(\mathrm{A}=\mathrm{X}) * \mathrm{P}(\mathrm{B}=\mathrm{X}) * \mathrm{P}(\mathrm{C}=\mathrm{X})$ \\
\hline E2 & $\mathrm{A}, \mathrm{B}$ & $\mathrm{C}$ & $\mathrm{P}(\mathrm{A}=\mathrm{X}) * \mathrm{P}(\mathrm{B}=\mathrm{X}) * \mathrm{P}(\mathrm{C}<\mathrm{X})$ \\
\hline E3 & $\mathrm{A}, \mathrm{C}$ & $\mathrm{B}$ & $\mathrm{P}(\mathrm{A}=\mathrm{X}) * \mathrm{P}(\mathrm{B}<\mathrm{X}) * \mathrm{P}(\mathrm{C}=\mathrm{X})$ \\
\hline E4 & $\mathrm{B}, \mathrm{C}$ & $\mathrm{A}$ & $\mathrm{P}(\mathrm{A}<\mathrm{X}) * \mathrm{P}(\mathrm{B}=\mathrm{X}) * \mathrm{P}(\mathrm{C}=\mathrm{X})$ \\
\hline E5 & $\mathrm{A}$ & $\mathrm{B}, \mathrm{C}$ & $\mathrm{P}(\mathrm{A}=\mathrm{X}) * \mathrm{P}(\mathrm{B}<\mathrm{X}) * \mathrm{P}(\mathrm{C}<\mathrm{X})$ \\
\hline E6 & $\mathrm{B}$ & $\mathrm{A}, \mathrm{C}$ & $\mathrm{P}(\mathrm{A}<\mathrm{X}) * \mathrm{P}(\mathrm{B}=\mathrm{X}) * \mathrm{P}(\mathrm{C}<\mathrm{X})$ \\
\hline E7 & $\mathrm{C}$ & $\mathrm{A}, \mathrm{B}$ & $\mathrm{P}(\mathrm{A}<\mathrm{X}) * \mathrm{P}(\mathrm{B}<\mathrm{X}) * \mathrm{P}(\mathrm{C}=\mathrm{X})$ \\
\hline
\end{tabular}

Probability events and their probabilities for a network consisting of four paths are shown in Table 2 . Number of distinct events can be listed as 3, 7, and 15 for the network with 2, 3, and 4 paths respectively. It is seen that the number of events is equal to the $2^{n}-1$, where $n$ is the number of paths in a network. A path can be critical or noncritical; therefore a path produces 2 distinct events. For a network consisting of $n$ paths $2^{n}$ distinct events can be produced. However, in a network there must be at least one critical path. Therefore the event in which all of the paths are noncritical is eliminated and the number of distinct events becomes $2^{n}-1$.

\subsection{Formation of distinct events}

Number of combinations increases exponentially when the number of paths increases. Manually formation and computation of distinct events is not practical; therefore an algorithm is generated for computerized computations. Table 2 shows the combinations for a network consisting of 4 paths. There is a systematic relationship at the formations of distinct events. If there are $n$ paths in a network, the critical path patterns can be divided into $n$ parts as shown in Table 2. The first row of $i^{\text {th }}$ part contains $2^{\mathrm{i}-1}$ events which contain $i^{\text {th }}$ path. In this case, first path is path $\mathrm{D}$ and the fourth path is path $\mathrm{A}$. At the first part $\mathrm{i}=1$ and it contains $2^{1}-1=1$ events which is formed by only one critical path. The second part contains $2^{2}-1=3$ events which are formed by combinations of two critical paths. These combinations can be formed by copying the path label in blue box to the top row of the second part just behind the first column. At this step three different critical path alternatives are formed which is equal to $2^{2}-1$. Third part can be formed by copying the $2^{\text {nd }}$ part which is bordered by claret red to second column of the top row of the $3^{\text {rd }}$ part. This cloning creates seven distinct events formed by combinations of three critical paths. If this procedure is repeated $n-1$ times, distinct events for $n$ paths can be formed. Path cloning is systematic and easy to be programmed. Flowchart of the path cloning algorithm is given in Figure 3.

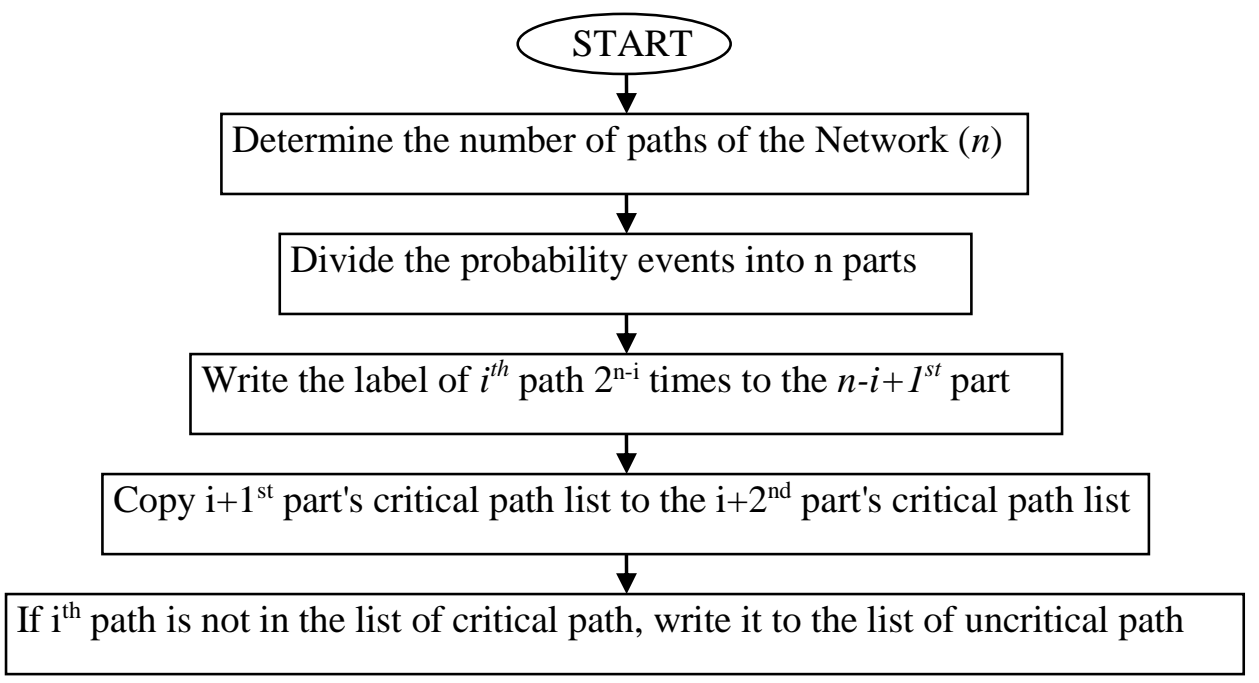

Figure 3. Flowchart of the cloning algorithm

Visual basic code is written to execute the described cloning algorithm which is given in Appendix 1. 
Table 2. Possible events for the 4-path network

\begin{tabular}{|c|c|c|c|c|c|}
\hline \multirow[b]{2}{*}{$4^{\text {th }}$ part } & \multirow{2}{*}{\begin{tabular}{|l|} 
Event \\
E1 \\
\end{tabular}} & \multicolumn{2}{|c|}{ Critical Paths } & Noncritical Paths & \multirow{2}{*}{$\begin{array}{c}\text { Probability of the Event } \\
\mathrm{P}(\mathrm{A}=\mathrm{X}) * \mathrm{P}(\mathrm{B}=\mathrm{X}) * \mathrm{P}(\mathrm{C}=\mathrm{X}) * \mathrm{P}(\mathrm{D}=\mathrm{X})\end{array}$} \\
\hline & & $\mathrm{A}: \overline{\mathrm{B}}$ & $\overline{\mathrm{C}}^{--} \overline{\mathrm{D}}-\overline{-}$ & - & \\
\hline & E2 & \begin{tabular}{|l:l}
$\mathrm{A}$ & $\mathrm{B}$ \\
\end{tabular} & $\mathrm{C}$ & $\mathrm{D}$ & $\mathrm{P}(\mathrm{A}=\mathrm{X}) * \mathrm{P}(\mathrm{B}=\mathrm{X}) * \mathrm{P}(\mathrm{C}=\mathrm{X}) * \mathrm{P}(\mathrm{D}<\mathrm{X})$ \\
\hline & E3 & $\mathrm{A}: \mathrm{B}$ & $\mathrm{D}$ & $\mathrm{C}$ & $\mathrm{P}(\mathrm{A}=\mathrm{X}) * \mathrm{P}(\mathrm{B}=\mathrm{X}) * \mathrm{P}(\mathrm{C}<\mathrm{X}) * \mathrm{P}(\mathrm{D}=\mathrm{X})$ \\
\hline & E4 & \begin{tabular}{|l:l}
$A$ & $B$ \\
\end{tabular} & & C D & $\mathrm{P}(\mathrm{A}=\mathrm{X}) * \mathrm{P}(\mathrm{B}=\mathrm{X}) * \mathrm{P}(\mathrm{C}<\mathrm{X}) * \mathrm{P}(\mathrm{D}<\mathrm{X})$ \\
\hline & E5 & $\mathrm{A}: \mathrm{C}$ & $\mathrm{D}$ & B & $\mathrm{P}(\mathrm{A}=\mathrm{X}) * \mathrm{P}(\mathrm{B}<\mathrm{X}) * \mathrm{P}(\mathrm{C}=\mathrm{X}) * \mathrm{P}(\mathrm{D}=\mathrm{X})$ \\
\hline & E6 & \begin{tabular}{|l:l}
$\mathrm{A}$ & $\mathrm{C}$ \\
\end{tabular} & & $\mathrm{B} \quad \mathrm{D}$ & $\mathrm{P}(\mathrm{A}=\mathrm{X}) * \mathrm{P}(\mathrm{B}<\mathrm{X}) * \mathrm{P}(\mathrm{C}=\mathrm{X}) * \mathrm{P}(\mathrm{D}<\mathrm{X})$ \\
\hline & E7 & $\begin{array}{l:l}A & D \\
\end{array}$ & & $\mathrm{~B} \quad \mathrm{C}$ & $\mathrm{P}(\mathrm{A}=\mathrm{X}) * \mathrm{P}(\mathrm{B}<\mathrm{X}) * \mathrm{P}(\mathrm{C}<\mathrm{X}) * \mathrm{P}(\mathrm{D}=\mathrm{X})$ \\
\hline & E8 & A & & B $\quad$ C $\quad$ D & $\mathrm{P}(\mathrm{A}=\mathrm{X}) * \mathrm{P}(\mathrm{B}<\mathrm{X}) * \mathrm{P}(\mathrm{C}<\mathrm{X}) * \mathrm{P}(\mathrm{D}<\mathrm{X})$ \\
\hline \multirow[t]{4}{*}{$3^{\text {rd }}$ part } & E9 & $\mathrm{B} \quad \overline{\mathrm{IC}}$ & & $\mathrm{A}$ & $\mathrm{P}(\mathrm{A}<\mathrm{X}) * \mathrm{P}(\mathrm{B}=\mathrm{X}) * \mathrm{P}(\mathrm{C}=\mathrm{X}) * \mathrm{P}(\mathrm{D}=\mathrm{X})$ \\
\hline & E10 & $\mathrm{B} \quad \mathrm{C}$ & & $\mathrm{A} \quad \mathrm{D}$ & $\mathrm{P}(\mathrm{A}<\mathrm{X}) * \mathrm{P}(\mathrm{B}=\mathrm{X}) * \mathrm{P}(\mathrm{C}=\mathrm{X}) * \mathrm{P}(\mathrm{D}<\mathrm{X})$ \\
\hline & E11 & \begin{tabular}{l|l}
$\mathrm{B}$ & $\mathrm{D}$ \\
\end{tabular} & & A C & $\mathrm{P}(\mathrm{A}<\mathrm{X}) * \mathrm{P}(\mathrm{B}=\mathrm{X}) * \mathrm{P}(\mathrm{C}<\mathrm{X}) * \mathrm{P}(\mathrm{D}=\mathrm{X})$ \\
\hline & E12 & $\mathrm{B}$ & & A $\quad$ C $\quad$ D & $\mathrm{P}(\mathrm{A}<\mathrm{X}) * \mathrm{P}(\mathrm{B}=\mathrm{X}) * \mathrm{P}(\mathrm{C}<\mathrm{X}) * \mathrm{P}(\mathrm{D}<\mathrm{X})$ \\
\hline \multirow[t]{2}{*}{$2^{\text {nd }}$ part } & E13 & \begin{tabular}{|l|l|l|} 
C & D & I \\
\end{tabular} & & A $\mathrm{B}$ & $\mathrm{P}(\mathrm{A}<\mathrm{X}) * \mathrm{P}(\mathrm{B}<\mathrm{X}) * \mathrm{P}(\mathrm{C}=\mathrm{X}) * \mathrm{P}(\mathrm{D}=\mathrm{X})$ \\
\hline & E14 & $\mathrm{C}$ & & A $\quad \mathrm{B} \quad \mathrm{D}$ & $\mathrm{P}(\mathrm{A}<\mathrm{X}) * \mathrm{P}(\mathrm{B}<\mathrm{X}) * \mathrm{P}(\mathrm{C}=\mathrm{X}) * \mathrm{P}(\mathrm{D}<\mathrm{X})$ \\
\hline $1^{\text {st }}$ part & E15 & 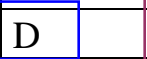 & & A $\mathrm{B} \quad \mathrm{C}$ & $\mathrm{P}(\mathrm{A}<\mathrm{X}) * \mathrm{P}(\mathrm{B}<\mathrm{X}) * \mathrm{P}(\mathrm{C}<\mathrm{X}) * \mathrm{P}(\mathrm{D}=\mathrm{X})$ \\
\hline
\end{tabular}

\subsection{Computation of probability}

Probability computations are performed by numeric integration; therefore, the time range when the project can be finished is divided into portions with equal interval. Probability of a path being critical is obtained by the z-score of the specific time. Z-score of specific completion time is computed by the mean and standard deviation of the path, then probability of z-score is obtained by z-table. In this study probabilities are computed by NORM.S.DIST function of Microsoft Excel.

If a path is noncritical, then the path should be finished before the examined time interval. Probability of a path being noncritical for specific completion time is computed by considering the probability of finishing the path before the specific time. In this case, the probability is computed by the $\mathrm{z}$-score of the previous time interval. Probability of an event is computed by multiplying all of the probabilities of the states of the paths which form the event. It is necessary to compute the probabilities of $2^{n}-1$ probability events.

\section{CASE STUDIES}

In this study, uncertainty of project duration is examined by four hypothetical and one real test problems.

\subsection{Test Problem 1}

First problem consists of ten activities and the activity on arrow diagram of the project is given in Figure 4. The network consists of three paths. Path A-B-F-G-I, Path A-C-D-G-I, and Path A-C-E-H-J are represented as Path-1, Path-2 and Path-3 respectively.

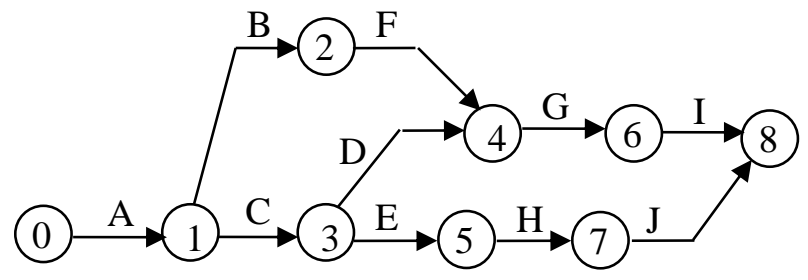

Figure 4. Activity on arrow diagram of the first problem 
Optimum, normal, and pessimistic duration estimations of the activities of the first sample problem are given in Table 3. First column represents the activity label, columns 2 to 4 represent the optimistic, normal and pessimistic activity durations respectively. First four columns define the test problem. Expected duration and the standard deviation of the duration of the activities are represented in the columns 5 and 6 . Expected duration is computed by $(a+4 m+b) / 6$, and standard deviation is computed by $(b-a) / 3.2$. Early event time (EET) and late event time (LET) of the start node and end node of the activities are given in columns 8 to 11. Final column represent the total float time.

Table 3. Data of first case problem

\begin{tabular}{|l|l|l|l|l|l|l|l|l|l|l|l|}
\hline Activity & a & $\mathbf{m}$ & $\mathbf{b}$ & Dur & Std Dev & Var & EET $_{\mathbf{i}}$ & LET $_{\mathbf{i}}$ & $\mathbf{E E T}_{\mathbf{j}}$ & $\mathbf{L E T}_{\mathbf{j}}$ & Float \\
\hline A & 1 & 2 & 3 & 2 & 0.625 & 0.391 & 0 & 0 & 2 & 2 & 0 \\
\hline B & 4 & 6 & 8 & 6 & 1.250 & 1.563 & 2 & 2 & 8 & 26 & 18 \\
\hline C & 7 & 8 & 9 & 8 & 0.625 & 0.391 & 2 & 2 & 10 & 10 & 0 \\
\hline D & 10 & 11 & 12 & 11 & 0.625 & 0.391 & 10 & 10 & 21 & 34 & 13 \\
\hline E & 13 & 14 & 15 & 14 & 0.625 & 0.391 & 10 & 10 & 24 & 24 & 0 \\
\hline F & 7 & 8 & 9 & 8 & 0.625 & 0.391 & 8 & 26 & 21 & 34 & 18 \\
\hline G & 4 & 5 & 6 & 5 & 0.625 & 0.391 & 21 & 34 & 26 & 39 & 13 \\
\hline H & 12 & 15 & 18 & 15 & 1.875 & 3.516 & 24 & 24 & 39 & 39 & 0 \\
\hline I & 7 & 9 & 11 & 9 & 1.250 & 1.563 & 26 & 39 & 48 & 48 & 13 \\
\hline J & 8 & 9 & 10 & 9 & 0.625 & 0.391 & 39 & 39 & 48 & 48 & 0 \\
\hline
\end{tabular}

Mean and standard deviation of the paths are computed as $30 \pm 2.07,35 \pm 1.77$, and $48 \pm 2.25$ days for the Paths 1, 2, and 3 respectively. In this case problem, Path-3 is the critical path and the remaining two paths are significantly shorter than the critical path. Therefore, the effects of the shorter paths are expected to be ignorable and this situation is examined. PERT ignores the shorter paths and provides $48 \pm 2.25$ days of mean and standard deviation for the first case problem meaning that Path 3 is $100 \%$ critical path. Project duration and its standard deviation are estimated by Modified PERT with 5 days of partition size and computations are given in Table 4.

Table 4. Modified PERT computations with 5-day partitioning

\begin{tabular}{|l|l|l|l|l|l|l|l|l|}
\hline Int. & Mean & $\begin{array}{l}\mathbf{P a t h}-1 \\
\mathbf{P}\left(\mathbf{T}_{\mathbf{1}} \leq \mathbf{X}\right)\end{array}$ & $\begin{array}{l}\mathbf{P a t h}-2 \\
\mathbf{P}\left(\mathbf{T}_{\mathbf{2}} \leq \mathbf{X}\right)\end{array}$ & $\begin{array}{l}\mathbf{P a t h - 3} \\
\mathbf{P}\left(\mathbf{T}_{\mathbf{3}} \leq \mathbf{X}\right)\end{array}$ & $\mathbf{P}(\mathbf{T} \leq \mathbf{X})$ & $\mathbf{P}(\mathbf{T}=\mathbf{X})$ & $\mathbf{P}(\mathbf{T}=\mathbf{X})^{*} \mathbf{x}_{\mathbf{i}}$ & $\mathbf{P}(\mathbf{T}=\mathbf{X}) *\left(\overline{\mathbf{x}}-\mathbf{x}_{\mathbf{i}}\right)^{2}$ \\
\hline & 17.5 & 0 & 0 & 0 & 0 & 0 & & \\
\hline 20 & 22.5 & $1.48 \mathrm{E}-04$ & $7.69 \mathrm{E}-13$ & $5.47 \mathrm{E}-30$ & $6.24 \mathrm{E}-46$ & $6.24 \mathrm{E}-46$ & $1.09 \mathrm{E}-44$ & $4.90 \mathrm{E}-43$ \\
\hline 25 & 27.5 & $1.14 \mathrm{E}-01$ & $1.10 \mathrm{E}-05$ & $4.64 \mathrm{E}-20$ & $5.84 \mathrm{E}-26$ & $5.84 \mathrm{E}-26$ & $1.31 \mathrm{E}-24$ & $3.09 \mathrm{E}-23$ \\
\hline 30 & 32.5 & $8.86 \mathrm{E}-01$ & $7.86 \mathrm{E}-02$ & $3.03 \mathrm{E}-12$ & $2.11 \mathrm{E}-13$ & $2.11 \mathrm{E}-13$ & $5.80 \mathrm{E}-12$ & $6.85 \mathrm{E}-11$ \\
\hline 35 & 37.5 & $1.00 \mathrm{E}+00$ & $9.21 \mathrm{E}-01$ & $1.59 \mathrm{E}-06$ & $1.46 \mathrm{E}-06$ & $1.46 \mathrm{E}-06$ & $4.75 \mathrm{E}-05$ & $2.47 \mathrm{E}-04$ \\
\hline 40 & 42.5 & $1.00 \mathrm{E}+00$ & $1.00 \mathrm{E}+00$ & $7.33 \mathrm{E}-03$ & $7.33 \mathrm{E}-03$ & $7.33 \mathrm{E}-03$ & $2.75 \mathrm{E}-01$ & $4.71 \mathrm{E}-01$ \\
\hline 45 & 47.5 & $1.00 \mathrm{E}+00$ & $1.00 \mathrm{E}+00$ & $4.12 \mathrm{E}-01$ & $4.12 \mathrm{E}-01$ & $4.05 \mathrm{E}-01$ & $1.72 \mathrm{E}+01$ & $3.69 \mathrm{E}+00$ \\
\hline 50 & 52.5 & $1.00 \mathrm{E}+00$ & $1.00 \mathrm{E}+00$ & $9.77 \mathrm{E}-01$ & $9.77 \mathrm{E}-01$ & $5.65 \mathrm{E}-01$ & $2.68 \mathrm{E}+01$ & $2.22 \mathrm{E}+00$ \\
\hline 55 & 57.5 & $1.00 \mathrm{E}+00$ & $1.00 \mathrm{E}+00$ & $1.00 \mathrm{E}+00$ & $1.00 \mathrm{E}+00$ & $2.29 \mathrm{E}-02$ & $1.20 \mathrm{E}+00$ & $1.12 \mathrm{E}+00$ \\
\hline 60 & 62.5 & $1.00 \mathrm{E}+00$ & $1.00 \mathrm{E}+00$ & $1.00 \mathrm{E}+00$ & $1.00 \mathrm{E}+00$ & $1.24 \mathrm{E}-05$ & $7.16 \mathrm{E}-04$ & $1.79 \mathrm{E}-03$ \\
\hline 65 & 67.5 & $1.00 \mathrm{E}+00$ & $1.00 \mathrm{E}+00$ & $1.00 \mathrm{E}+00$ & $1.00 \mathrm{E}+00$ & $6.19 \mathrm{E}-11$ & $3.87 \mathrm{E}-09$ & $1.79 \mathrm{E}-08$ \\
\hline
\end{tabular}

In Table 4, first column represents the borders of the partitions. Second column represents the mean values of the partitions which are called class marks. Mean values for the first and the last row contains truncation errors. In the first row, probabilities of completion of the paths are assumed to be zero and in the last row these are assumed to be one. Following three columns provide the probabilities of finishing the paths within the corresponding time for the paths 1,2 , and 3 respectively. Sixth column provides the probability of finishing the network within the corresponding time. This column is computed by multiplying the probability values of Paths 1,2, and 3. To complete a project, all of the paths should be completed. Probability of occurrence of multiple events is computed by multiplying the probability of occurrence of each event. Seventh column represents the probability of completion of the project within specific time. $i^{\text {th }}$ 
row of seventh column is computed by subtracting $(i-1)^{s t}$ row from the $i^{\text {th }}$ row of the sixth column. Probability of finishing the project earlier than 17.5 days is assumed to be zero and in this example truncation error is less than $10^{-46}$. Eighth column is obtained by multiplying the second column with seventh column. Sum of the rows of the eighth column gives the mean project duration. In this example the sum is 45.52 days. Ninth column is obtained by multiplying the seventh column by the square of the difference of mean project duration and the class marks.

Step size affects the accuracy of numeric integration. In order to examine the effect of size of partitioning, 5 different partition sizes $(5,2,1,0.5,0.2$ days) are tested without changing the range of numeric integration. Obtained results with the mentioned step sizes are shown in Table 5.

Table 5. Effect of partition size for Modified PERT

\begin{tabular}{|l|c|c|c|c|c|}
\hline Partition Size & $\mathbf{5}$ & $\mathbf{2}$ & $\mathbf{1}$ & $\mathbf{0 . 5}$ & $\mathbf{0 . 2}$ \\
\hline Mean Duration & 45.52 & 47.00 & 47.50 & 47.75 & 47.90 \\
\hline Standard Deviation & 2.74 & 2.33 & 2.27 & 2.26 & 2.25 \\
\hline
\end{tabular}

Mean project duration approaches to 48 days when partition size is reduced. Modified PERT would give the same results with PERT if infinitely small step size is chosen. This is because the duration of noncritical paths are significantly smaller than the critical path and the contribution of the noncritical paths are negligible. The results indicate that partition size should be chosen as small as possible to obtain accurate results.

Probability of being critical path is computed by the proposed improvement on Modified PERT. Table 1 lists the events for 3-path network. In order to compute the probability of a path being critical, all of the events are examined. Due to space limitations, computations for five events are given in Table 6.

Table 6. Probability computations of the paths being critical path

\begin{tabular}{|l|l|l|l|l|l|l|l|l|l|}
\hline Int & Mean & $\mathbf{P}\left(\mathbf{T}_{\mathbf{1}}=\mathbf{X}\right)$ & $\mathbf{P}\left(\mathbf{T}_{\mathbf{2}}=\mathbf{X}\right)$ & $\mathbf{P}\left(\mathbf{T}_{\mathbf{3}}=\mathbf{X}\right)$ & $\mathbf{E} 1$ & $\mathbf{E 2}$ & $\mathbf{E 3}$ & $\mathbf{E 5}$ & $\mathbf{E} 7$ \\
\hline & 17.5 & 0 & 0 & 0 & & & & & \\
\hline 20 & 22.5 & $1.48 \mathrm{E}-04$ & $7.69 \mathrm{E}-13$ & $5.47 \mathrm{E}-30$ & $6.24 \mathrm{E}-46$ & $0.00 \mathrm{E}+00$ & $0.00 \mathrm{E}+00$ & $0.00 \mathrm{E}+00$ & $0.00 \mathrm{E}+00$ \\
\hline 25 & 27.5 & $1.14 \mathrm{E}-01$ & $1.10 \mathrm{E}-05$ & $4.64 \mathrm{E}-20$ & $5.83 \mathrm{E}-26$ & $6.88 \mathrm{E}-36$ & $4.06 \mathrm{E}-33$ & $4.79 \mathrm{E}-43$ & $5.29 \mathrm{E}-36$ \\
\hline 30 & 32.5 & $7.72 \mathrm{E}-01$ & $7.86 \mathrm{E}-02$ & $3.03 \mathrm{E}-12$ & $1.84 \mathrm{E}-13$ & $2.82 \mathrm{E}-21$ & $2.58 \mathrm{E}-17$ & $3.96 \mathrm{E}-25$ & $3.81 \mathrm{E}-18$ \\
\hline 35 & 37.5 & $1.14 \mathrm{E}-01$ & $8.43 \mathrm{E}-01$ & $1.59 \mathrm{E}-06$ & $1.52 \mathrm{E}-07$ & $2.90 \mathrm{E}-13$ & $1.42 \mathrm{E}-08$ & $2.71 \mathrm{E}-14$ & $1.10 \mathrm{E}-07$ \\
\hline 40 & 42.5 & $1.48 \mathrm{E}-04$ & $7.86 \mathrm{E}-02$ & $7.33 \mathrm{E}-03$ & $8.55 \mathrm{E}-08$ & $1.85 \mathrm{E}-11$ & $1.00 \mathrm{E}-06$ & $2.17 \mathrm{E}-10$ & $6.75 \mathrm{E}-03$ \\
\hline 45 & 47.5 & $8.19 \mathrm{E}-10$ & $1.10 \mathrm{E}-05$ & $4.05 \mathrm{E}-01$ & $3.66 \mathrm{E}-15$ & $6.63 \mathrm{E}-17$ & $3.31 \mathrm{E}-10$ & $6.00 \mathrm{E}-12$ & $4.05 \mathrm{E}-01$ \\
\hline 50 & 52.5 & $0.00 \mathrm{E}+0$ & $7.69 \mathrm{E}-13$ & $5.65 \mathrm{E}-01$ & $0.00 \mathrm{E}+00$ & $0.00 \mathrm{E}+0$ & $0.00 \mathrm{E}+0$ & $0.00 \mathrm{E}+0$ & $5.65 \mathrm{E}-01$ \\
\hline 55 & 57.5 & $0.00 \mathrm{E}+0$ & $0.00 \mathrm{E}+0$ & $2.29 \mathrm{E}-02$ & $0.00 \mathrm{E}+00$ & $0.00 \mathrm{E}+0$ & $0.00 \mathrm{E}+0$ & $0.00 \mathrm{E}+0$ & $2.29 \mathrm{E}-02$ \\
\hline 60 & 62.5 & $0.00 \mathrm{E}+0$ & $0.00 \mathrm{E}+0$ & $1.24 \mathrm{E}-05$ & $0.00 \mathrm{E}+00$ & $0.00 \mathrm{E}+0$ & $0.00 \mathrm{E}+0$ & $0.00 \mathrm{E}+0$ & $1.24 \mathrm{E}-05$ \\
\hline 65 & 67.5 & $0.00 \mathrm{E}+0$ & $0.00 \mathrm{E}+0$ & $6.19 \mathrm{E}-11$ & $0.00 \mathrm{E}+00$ & $0.00 \mathrm{E}+0$ & $0.00 \mathrm{E}+0$ & $0.00 \mathrm{E}+0$ & $6.19 \mathrm{E}-11$ \\
\hline & & & & TOTAL & $\mathbf{2 . 3 7 E - 0 7}$ & $\mathbf{1 . 8 8 E - 1 1}$ & $\mathbf{1 . 0 1 6 E}-6$ & $\mathbf{2 . 2 3 E - 1 0}$ & $\mathbf{0 . 9 9 9 4 2}$ \\
\hline
\end{tabular}

In Table 6, first two columns represent border of partitions and mean value of the partitions respectively. Third column represents the probability of completion of Path1 exactly at the defined time. $i^{\text {th }}$ row of third column of Table 6 is computed by subtracting the values of the $i^{\text {th }}$ and $(i-1)^{\text {th }}$ rows of the third column of Table 4. Fourth and fifth columns of Table 6 are computed by adopting the same procedure to the fourth and fifth columns of Table 4. Sixth column of Table 6 provides the probability computation for the event E1 given in Table 1. This event requires that paths 1,2, and 3 are critical paths. The value at the $i^{\text {th }}$ row of sixth column is obtained by multiplying the $i^{\text {th }}$ rows of the columns 3,4 , and 5 . The multiplication means that the all three paths are finished exactly at the examined time (class mark). Summation of the all of the rows gives $2.37 \mathrm{E}-07$, which is the probability of the paths 1,2 , and 3 are being critical at the same time.

Seventh row of Table 6 examines the case in which path 1 and 2 are critical paths, while path 3 is noncritical which is represented as E2 in Table 1. In this case probability of a path being noncritical is computed. The probability computation of noncritical path depends on the fact that the path should be finished earlier than 
the examined time. Therefore the probability of finishing the path before the examined class mark is obtained by the probability value of finishing the path within previous time mark. The noncritical paths should be finished earlier than the examined time so that previous time period is considered. Required probability is expressed as $\mathrm{P}\left(\mathrm{T}_{\mathrm{i}}<\mathrm{X}_{\mathrm{j}-1}\right)$ and this probability is given in Table 4. Probability values of the critical paths are multiplied by the $i^{\text {th }}$ row of Table 6 and the noncritical paths probability values are obtained from $(i-1)^{\text {th }}$ row of Table 4 . The last column represents the probability computation of the case in which paths 1 , and 2 are noncritical and path 3 is critical (E7). The probability of this case is very close to 1 since paths 1 and 2 have long float duration and it is very low probability that the aforementioned paths to be critical. Probability of a path being critical is computed by summing the probabilities of every path combination which contains the examined path. Probability of path1 being critical path is computed by summing the probability of events where path-1 is critical. Path1 becomes critical if any of the events E1, E2, E3, and E5 occur. Probability of path1 being critical path is obtained by summing the values of the columns 6 to 9 of Table 6 which is 1.254E-06.

Effect of partition size on the probability of being critical path is tested and the results are given in Table 7. Probability values of the third path are not affected considerably by the partition size. However, the ratio of change is important for paths 1 , and 2 respectively.

Table 7. Probabilities of the paths being critical

\begin{tabular}{|l|l|l|l|l|l|}
\hline \multicolumn{7}{|c|}{ Partition Size (Days) } \\
\hline & 5 & 2 & 1 & 0.5 & 0.2 \\
\hline $\mathbf{P}($ Path-1 is critical) & $1.254 \mathrm{E}-06$ & $2.254 \mathrm{E}-08$ & $5.996 \mathrm{E}-09$ & $3.292 \mathrm{E}-09$ & $2.365 \mathrm{E}-09$ \\
\hline $\mathbf{P}($ Path-2 is critical $)$ & 0.0005823 & $1.968 \mathrm{E}-05$ & $7.037 \mathrm{E}-06$ & $4.374 \mathrm{E}-06$ & $3.348 \mathrm{E}-06$ \\
\hline $\mathbf{P}($ Path-3 is critical $)$ & 0.9999998 & 0.9999992 & 0.9999986 & 0.9999981 & 0.9999976 \\
\hline
\end{tabular}

In order to compare findings of the study the first sample problem is analyzed by Monte Carlo Simulation with 100 sampling. The MCS is repeated 10 times and the mean of project duration and its uncertainty is computed as $47.544 \pm 0.693$ days. Deviation of project duration and its uncertainty are computed as 0.027 and 0.000 day which means that the results are stable. Probabilities of the paths being critical path are estimated as $0 \%, 0 \%$, and $100 \%$ for paths 1,2, and 3 respectively. Because of inadequate sample size, MCS underestimates the project duration and its uncertainty.

\subsection{Test Problem 2}

Second case problem consists of twelve activities and the activity on arrow diagram is given in Figure 5. The project contains three paths; A-C-E-H-K, B-D-F-I-K, and B-D-G-J-L.

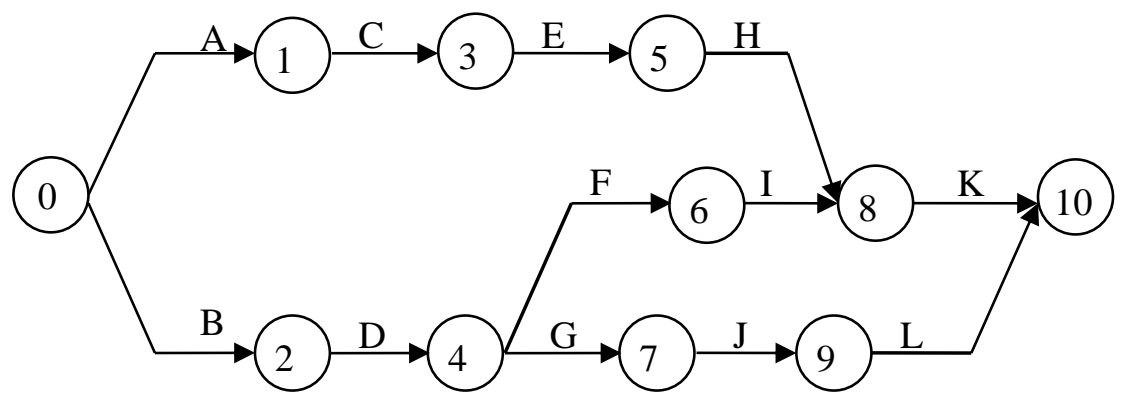

Figure 5. Activity on arrow diagram of the second problem

Optimistic, normal and pessimistic activity durations are given in Table 8. Durations of the paths are computed as $45 \pm 2.724,47 \pm 3.423$, and $49 \pm 3.248$ days respectively. Project data and CPM computations of the second case problem are given in Table 8 . In the second problem durations of the paths are close to each other and effects of noncritical paths are not ignorable. PERT gives $49 \pm 3.248$ days for the mean project duration and standard deviation. 
Table 8. Activity durations and event times of the second case problem

\begin{tabular}{|l|l|l|l|l|l|l|l|l|l|l|l|}
\hline Act. & $\mathbf{a}$ & $\mathbf{m}$ & $\mathbf{b}$ & Dur & St Dev & Var & EET $_{\mathbf{i}}$ & LET $_{\mathbf{i}}$ & $\mathbf{E E T}_{\mathbf{j}}$ & LET $_{\mathbf{j}}$ & Total Float \\
\hline A & 5 & 6 & 7 & 6 & 0.63 & 0.39 & 0 & 0 & 6 & 10 & 4 \\
\hline B & 4 & 7 & 10 & 7 & 1.88 & 3.52 & 0 & 0 & 7 & 7 & 0 \\
\hline C & 6 & 8 & 10 & 8 & 1.25 & 1.56 & 6 & 10 & 14 & 18 & 4 \\
\hline D & 7 & 9 & 11 & 9 & 1.25 & 1.56 & 7 & 7 & 16 & 16 & 0 \\
\hline E & 10 & 13 & 16 & 13 & 1.88 & 3.52 & 14 & 18 & 27 & 31 & 4 \\
\hline F & 8 & 10 & 12 & 10 & 1.25 & 1.56 & 16 & 16 & 26 & 28 & 2 \\
\hline G & 9 & 10 & 11 & 10 & 0.63 & 0.39 & 16 & 16 & 26 & 26 & 0 \\
\hline H & 7 & 8 & 9 & 8 & 0.63 & 0.39 & 27 & 31 & 37 & 39 & 4 \\
\hline I & 8 & 11 & 14 & 11 & 1.88 & 3.52 & 26 & 28 & 37 & 39 & 2 \\
\hline J & 9 & 11 & 13 & 11 & 1.25 & 1.56 & 26 & 26 & 37 & 37 & 0 \\
\hline K & 8 & 10 & 12 & 10 & 1.25 & 1.56 & 37 & 39 & 49 & 49 & 2 \\
\hline L & 9 & 12 & 15 & 12 & 1.88 & 3.52 & 37 & 37 & 49 & 49 & 0 \\
\hline
\end{tabular}

Duration and uncertainty of second case study problem is also estimated by Modified PERT and the results are given in Table 9. In this case problem step size of the numeric integration is investigated again. It is seen that selection of step size longer than 0.5 day causes important amount of numeric error. Therefore, step size should be taken as small as possible.

Table 9. Effect of partition size on the project duration estimation

\begin{tabular}{|l|l|l|l|l|l|}
\hline Partition Size (Days) & $\mathbf{5}$ & $\mathbf{2}$ & $\mathbf{1}$ & $\mathbf{0 . 5}$ & $\mathbf{0 . 2}$ \\
\hline Duration (Days) & 47.735 & 49.220 & 49.720 & 49.970 & 50.120 \\
\hline St. Dev. (Days) & 2.969 & 2.685 & 2.638 & 2.626 & 2.623 \\
\hline
\end{tabular}

Probabilities of the paths being critical path are computed for different step sizes and the results are given in Table 10. Second case problem reveals that the probabilities of the paths are affected more from numerical errors if their probability of being critical path is low. In addition to this, too large step size overestimates the probability of a path being critical path.

Table 10. Probabilities of paths being critical computed for the second sample problem

\begin{tabular}{|l|l|l|l|l|l|}
\hline Step Size (Days) & $\mathbf{5}$ & $\mathbf{2}$ & $\mathbf{1}$ & $\mathbf{0 . 5}$ & $\mathbf{0 . 2}$ \\
\hline $\mathbf{P}($ Path-1 is critical) & 0.262 & 0.151 & 0.121 & 0.108 & 0.101 \\
\hline $\mathbf{P}($ Path-2 is critical) & 0.509 & 0.383 & 0.340 & 0.319 & 0.307 \\
\hline $\mathbf{P}$ (Path-3 is critical) & 0.785 & 0.689 & 0.649 & 0.627 & 0.614 \\
\hline
\end{tabular}

Project duration and its uncertainty are estimated by MCS with 100, 500, and 2500 sample sizes. The analysis results are given in Table 11.

Table 11. Probabilities of paths being critical obtained by MCS for the second sample

\begin{tabular}{|l|l|l|l|l|l|}
\hline Repetition & Duration & Uncertainty & Path1 & Path2 & Path3 \\
\hline MCS100 & 49.391 & 2.776 & 0.129 & 0.226 & 0.645 \\
\hline MCS500 & 49.743 & 2.860 & 0.126 & 0.230 & 0.644 \\
\hline MCS2500 & 49.822 & 2.820 & 0.124 & 0.243 & 0.633 \\
\hline
\end{tabular}

Analysis results given in Table 11 reveal that selection of small iteration number causes underestimation of project duration. However, there is not such effect on the probabilities of being critical path. Obtained probabilities change randomly when compared with the iteration size. Average computation times for the analysis are measured as 5, 23, and 190 seconds for MCS100, MCS500, and MCS2500 respectively. In this case problem durations of the paths are closer to each other when compared with the previous case problem. Therefore, reliable solution requires relatively larger sample size in this case problem. Consequently, computational demand of MCS increases if dependable results are required. 


\subsection{Test Problem 3}

Third case study problem whose network diagram is given in Figure 6 consist of 17 activities.

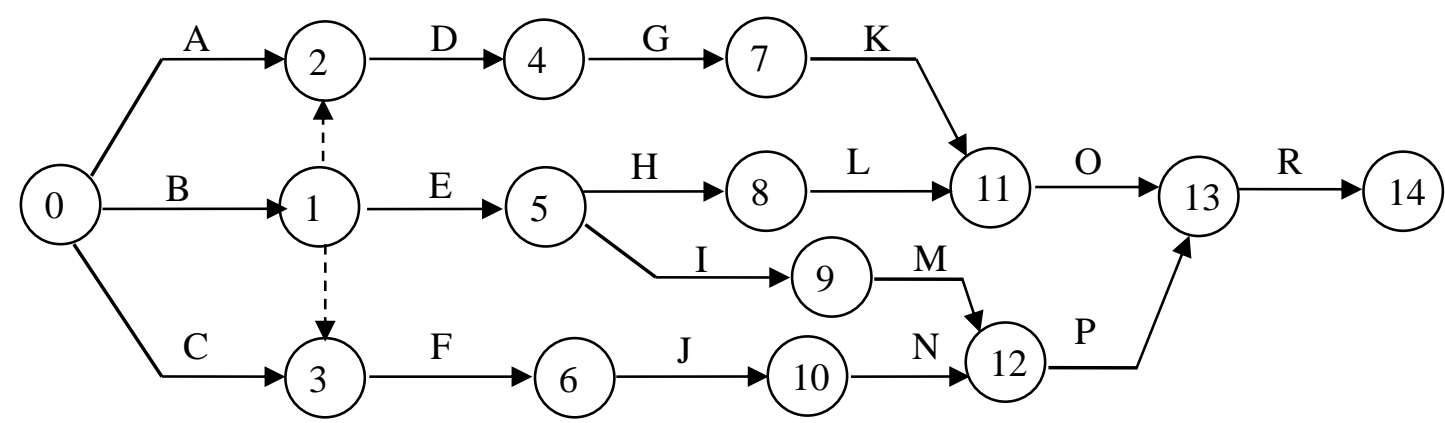

Figure 6. Activity on arrow diagram of the third problem

Activity durations and uncertainties are given in Table 12. The network consists of six paths; B-E-I-M-PR, B-E-H-L-O-R, A-D-G-K-O-R, B-D-G-K-O-R, B-F-J-N-P-R, and C-F-J-N-P-R. Durations and standard deviations of the paths are $68 \pm 2.88,60 \pm 2.52,52 \pm 3.13,51 \pm 3.01,50 \pm 2.52,50 \pm 2.36$ days respectively. Duration and its uncertainty of the project are computed as $68 \pm 2.88$ days by PERT.

Table 12. Activity durations and event times of the third case problem

\begin{tabular}{|l|l|l|l|l|l|l|l|l|l|l|l|}
\hline Act. & $\mathbf{a}$ & $\mathbf{m}$ & $\mathbf{b}$ & Dur. & Std. Dev. & Var. & EET $_{\mathbf{i}}$ & $\mathbf{L E T}_{\mathbf{i}}$ & $\mathbf{E E T}_{\mathbf{j}}$ & $\mathbf{L E T}_{\mathbf{j}}$ & Total Float \\
\hline $\mathrm{A}$ & 3 & 5 & 7 & 5 & 1.25 & 1.56 & 0 & 0 & 5 & 21 & 16 \\
\hline $\mathrm{B}$ & 2.5 & 4 & 5.5 & 4 & 0.94 & 0.88 & 0 & 0 & 4 & 4 & 0 \\
\hline C & 3.5 & 4 & 4.5 & 4 & 0.31 & 0.10 & 0 & 0 & 4 & 22 & 18 \\
\hline D & 7 & 10 & 13 & 10 & 1.88 & 3.52 & 5 & 21 & 15 & 31 & 16 \\
\hline E & 12 & 14 & 16 & 14 & 1.25 & 1.56 & 4 & 4 & 18 & 18 & 0 \\
\hline F & 5 & 7 & 9 & 7 & 1.25 & 1.56 & 4 & 22 & 11 & 29 & 18 \\
\hline G & 3 & 6 & 9 & 6 & 1.88 & 3.52 & 15 & 31 & 21 & 37 & 16 \\
\hline H & 7 & 9 & 11 & 9 & 1.25 & 1.56 & 18 & 18 & 27 & 35 & 8 \\
\hline I & 11 & 14 & 17 & 14 & 1.88 & 3.52 & 18 & 18 & 32 & 32 & 0 \\
\hline J & 8 & 10 & 12 & 10 & 1.25 & 1.56 & 11 & 29 & 21 & 39 & 18 \\
\hline K & 8 & 9 & 10 & 9 & 0.63 & 0.39 & 21 & 37 & 38 & 46 & 16 \\
\hline L & 9 & 11 & 13 & 11 & 1.25 & 1.56 & 27 & 35 & 38 & 46 & 8 \\
\hline M & 14 & 16 & 18 & 16 & 1.25 & 1.56 & 32 & 32 & 48 & 48 & 0 \\
\hline N & 7 & 9 & 11 & 9 & 1.25 & 1.56 & 21 & 39 & 48 & 48 & 18 \\
\hline O & 8 & 9 & 10 & 9 & 0.63 & 0.39 & 38 & 46 & 55 & 55 & 8 \\
\hline P & 6 & 7 & 8 & 7 & 0.63 & 0.39 & 48 & 48 & 55 & 55 & 0 \\
\hline R & 12 & 13 & 14 & 13 & 0.63 & 0.39 & 55 & 55 & 68 & 68 & 0 \\
\hline
\end{tabular}

Project duration and its uncertainty are computed by Modified PERT with different step size and results are given in Table 13. Effect of partition size is the same with the previous case studies.

Table 13. Effect of partition size on the project duration estimation

\begin{tabular}{|l|l|l|l|l|l|}
\hline Partition Size (Days) & $\mathbf{5}$ & $\mathbf{2}$ & $\mathbf{1}$ & $\mathbf{0 . 5}$ & $\mathbf{0 . 2}$ \\
\hline Duration (Days) & 65.528 & 67.025 & 67.525 & 67.775 & 67.925 \\
\hline Standard Dev. (Days) & 3.188 & 2.897 & 2.854 & 2.843 & 2.840 \\
\hline
\end{tabular}

In this case study, project has abundant number of paths with long time differences. Therefore some of the paths can be eliminated without significant error. In this case problem effect of path elimination on the probabilities of the paths being critical is examined. Sample problem contains 6 paths, so 63 path combinations are examined. Step size is taken as 0.2 day for numeric integration and one analysis is completed in 2 seconds on i5 CPU when six paths are considered. Gradually the shortest path is eliminated and the analysis is repeated. The analysis results are given in Table 14. 
Table 14. Effect of considered path numbers on the probabilities

\begin{tabular}{|l|l|l|l|l|l|l|}
\hline & \multicolumn{7}{|c|}{ Number of Examined Paths } \\
\hline & $\mathbf{6}$ & $\mathbf{5}$ & $\mathbf{4}$ & $\mathbf{3}$ & $\mathbf{2}$ & $\mathbf{1}$ \\
\hline $\mathbf{P}(\mathbf{P} 1$ is critical $)$ & 0.982783 & 0.982783 & 0.982783 & 0.982792 & 0.982833 & 1 \\
\hline $\mathbf{P}(\mathbf{P}$ is critical $)$ & 0.019503 & 0.019503 & 0.019503 & 0.019505 & 0.019515 & \\
\hline $\mathbf{P}(\mathbf{P 3}$ is critical $)$ & $5.92 \mathrm{E}-05$ & $5.92 \mathrm{E}-05$ & $5.92 \mathrm{E}-05$ & $5.93 \mathrm{E}-05$ & & \\
\hline $\mathbf{P}(\mathbf{P} 4$ is critical $)$ & $1.38 \mathrm{E}-05$ & $1.38 \mathrm{E}-05$ & $1.38 \mathrm{E}-05$ & & & \\
\hline $\mathbf{P}(\mathbf{P 5}$ is critical $)$ & $4.05 \mathrm{E}-07$ & $4.05 \mathrm{E}-07$ & & & & \\
\hline $\mathbf{P}(\mathbf{P}$ is critical $)$ & $1.63 \mathrm{E}-07$ & & & & & \\
\hline
\end{tabular}

First column of Table 14 represents the headings of the probability of a path being critical path. Second column represents the probabilities of the paths being critical when six paths are considered. At the top row probabilities of the first path being critical path is given and similarly at the bottom row probabilities of the sixth path being critical path are given. Third column represents the probabilities of the paths being critical when the longest five paths are considered and headings of the columns are written according to the number of considered path. When the path is eliminated its probability of being critical path cannot be computed therefore, the corresponding cells are kept empty. It is seen that paths $3,4,5$, and 6 have very diminutive effect on the probabilities of being critical path of the paths 1 , and 2. It is seen that elimination of a path increases the probabilities of being critical path of the remaining paths.

MCS is implemented with 500 iterations for the third case study problem. Project duration is estimated as $67.87 \pm 2.93$ days. Duration estimation is relatively more stable when compared with the second case study problem. The reason of this can be explained as the duration gaps between the examined paths. Probability of paths being critical is computed as 0.997 and 0.003 for paths 1, and 2 respectively. Probabilities of being critical path of the remaining paths are estimated as 0. MCS and the proposed algorithm give similar results.

\subsection{Test Problem 4}

Fourth test problem is a real problem obtained from United States Air Force Ballistic Missile Development program (page II-7) [28]. The case problem consists of 16 activities and 11 nodes. The problem can be obtained from the manual given in the reference section so that the network is not given. Data about the activity durations is given in Table 15 .

Table 15. Data of case problem 4

\begin{tabular}{|l|l|l|l|l|l|l|l|l|}
\hline $\begin{array}{l}\text { Start } \\
\text { Node }\end{array}$ & $\begin{array}{l}\text { End } \\
\text { Node }\end{array}$ & Activity & a & m & b & Dur & $\begin{array}{l}\text { Standard } \\
\text { Deviation }\end{array}$ & Var \\
\hline 0 & 1 & A & 15 & 22 & 35 & $\mathbf{2 3}$ & 6.250 & 39.063 \\
\hline 0 & 2 & B & 4 & 5 & 12 & $\mathbf{6}$ & 2.500 & 6.250 \\
\hline 0 & 3 & C & 7 & 10 & 13 & $\mathbf{1 0}$ & 1.875 & 3.516 \\
\hline 1 & 9 & D & $\mathbf{0}$ & $\mathbf{0}$ & $\boldsymbol{0}$ & $\mathbf{0}$ & 0.000 & 0.000 \\
\hline 2 & 4 & E & 13 & 19 & 31 & $\mathbf{2 0}$ & 5.625 & 31.641 \\
\hline 3 & 4 & F & 45 & 50 & 55 & $\mathbf{5 0}$ & 3.125 & 9.766 \\
\hline 3 & 5 & G & 36 & 40 & 56 & $\mathbf{4 2}$ & 6.250 & 39.063 \\
\hline 3 & 6 & H & $\mathbf{2 4}$ & $\mathbf{3 3}$ & $\mathbf{5 4}$ & $\mathbf{3 5}$ & 9.375 & 87.891 \\
\hline 4 & 8 & I & 10 & 12 & 20 & $\mathbf{1 3}$ & 3.125 & 9.766 \\
\hline 5 & 7 & J & 5 & 9 & 19 & $\mathbf{1 0}$ & 4.375 & 19.141 \\
\hline 6 & 7 & K & 5 & 7 & 9 & $\mathbf{7}$ & 1.250 & 1.563 \\
\hline 8 & 10 & L & $\mathbf{3}$ & $\mathbf{5}$ & 7 & $\mathbf{5}$ & 1.250 & 1.563 \\
\hline 10 & 11 & M & 3 & 9 & 9 & $\mathbf{8}$ & 1.875 & 3.516 \\
\hline 8 & 9 & N & 0 & 0 & 0 & $\mathbf{0}$ & 0.000 & 0.000 \\
\hline 9 & 11 & O & 2 & 5 & 8 & $\mathbf{5}$ & 1.875 & 3.516 \\
\hline 2 & 3 & P & $\boldsymbol{1}$ & $\boldsymbol{1}$ & $\boldsymbol{1}$ & $\mathbf{1}$ & 0.000 & 0.000 \\
\hline
\end{tabular}


Project duration and its standard deviation is obtained as $88 \pm 8.75$ weeks by PERT. The test problem is analyzed by Ang's PERT method and the results are given in Table 16.

Table 16. Effect of partition size on the project duration estimation

\begin{tabular}{|l|c|c|c|c|c|}
\hline Partition Size (Weeks) & $\mathbf{5}$ & $\mathbf{2}$ & $\mathbf{1}$ & $\mathbf{0 . 5}$ & $\mathbf{0 . 2}$ \\
\hline Duration (Weeks) & 92.15 & 93.65 & 94.15 & 94.40 & 94.55 \\
\hline Standard Dev. (Weeks) & 5.70 & 5.54 & 5.52 & 5.51 & 5.51 \\
\hline
\end{tabular}

It is seen that when step size is decreased, duration increases while standard deviation decreases. All of the obtained durations are longer and standard deviations are less than the crude PERT method. The case problem is analyzed by the proposed method and the paths given in Table 17 are detected. Detected paths are listed in descending order with respected to their deterministic durations. The last three paths have significantly shorter durations and they are eliminated.

Table 17. Paths of the fourth case problem

\begin{tabular}{|c|l|l|l|l|}
\hline No & Path & Duration & \multicolumn{1}{|c|}{ Variance } & \multicolumn{1}{|c|}{ Std Dev } \\
\hline 1 & C-G-J-I-L-M & 88 & 76.56 & 8.75 \\
\hline 2 & C-F-I-L-M & 86 & 28.13 & 5.30 \\
\hline 3 & B-P-G-J-I-L-M & 85 & 79.30 & 8.90 \\
\hline 4 & B-P-F-I-L-M & 83 & 30.86 & 5.56 \\
\hline 5 & C-G-J-I-N-O & 80 & 75.00 & 8.66 \\
\hline 6 & C-H-K-I-L-M & 78 & 107.81 & 10.38 \\
\hline 7 & C-F-I-N-O & 78 & 26.56 & 5.15 \\
\hline 8 & B-P-G-J-I-N-O & 77 & 77.73 & 8.82 \\
\hline 9 & B-P-F-I-N-O & 75 & 29.30 & 5.41 \\
\hline 10 & C-H-K-I-N-O & 70 & 106.25 & 10.31 \\
\hline 11 & B-E-I-L-M & 52 & 52.73 & 7.26 \\
\hline 12 & $B-E-I-N-O$ & 44 & 51.17 & 7.15 \\
\hline 13 & $A-D-O$ & 28 & 42.58 & 6.53 \\
\hline
\end{tabular}

The probabilities of the paths being critical path are estimated by taking step size as 0.2 . The first analysis considers all of the 10 paths and the path with the shortest deterministic duration is eliminated step by step. Analysis results are shown in Table 18.

Table 18. Probabilities of being critical path of the fourth case study problem

\begin{tabular}{|c|c|c|c|c|c|c|c|c|c|c|}
\hline $\begin{array}{c}\text { No of } \\
\text { Paths }\end{array}$ & $\mathbf{1 0}$ & $\mathbf{9}$ & $\mathbf{8}$ & $\mathbf{7}$ & $\mathbf{6}$ & $\mathbf{5}$ & $\mathbf{4}$ & $\mathbf{3}$ & $\mathbf{2}$ & $\mathbf{1}$ \\
\hline CT & 507 & 213 & 107 & 62 & 38 & 13 & 5 & 3 & $<1$ & $<1$ \\
\hline Path-1 & 0.3367 & 0.3407 & 0.3413 & 0.3529 & 0.3553 & 0.3811 & 0.4105 & 0.4459 & 0.5813 & 1 \\
\hline Path-2 & 0.1558 & 0.1595 & 0.1603 & 0.1714 & 0.1745 & 0.1979 & 0.2276 & 0.2728 & 0.4263 & \\
\hline Path-3 & 0.2132 & 0.2160 & 0.2165 & 0.2247 & 0.2265 & 0.2446 & 0.2657 & 0.2920 & & \\
\hline Path-4 & 0.0708 & 0.0728 & 0.0733 & 0.0791 & 0.0810 & 0.0932 & 0.1094 & & & \\
\hline Path-5 & 0.0817 & 0.0831 & 0.0834 & 0.0875 & 0.0886 & 0.0975 & & & & \\
\hline Path-6 & 0.0834 & 0.0846 & 0.0848 & 0.0883 & 0.0891 & & & & & \\
\hline Path-7 & 0.0097 & 0.0101 & 0.0103 & 0.0116 & & & & & & \\
\hline Path-8 & 0.0451 & 0.0459 & 0.0461 & & & & & & & \\
\hline Path-9 & 0.0033 & 0.0034 & & & & & & & & \\
\hline Path-10 & 0.0167 & & & & & & & & & \\
\hline
\end{tabular}

Probabilities of being critical path of the ten paths are given in the second column. The computation duration is measured as 507 seconds for this analysis. The numerical integration and the too many number of path combinations are the main reason of long computation duration. When the probabilities of the paths 
being critical are examined it is seen that path-4, path-7, and path 9 have low probabilities because of their low variance of path duration. Tenth path is eliminated and the analysis is repeated by the remaining nine paths. The results are very similar to the previous analysis but there is a slight increase in the probabilities because by eliminating the tenth path it is assumed that the probability of tenth path being critical is zero and the ignored probability is shared by the remaining paths. This elimination halved the computational demand and the analysis duration is measured as 213 seconds.

Elimination of ninth path also does not affect the probabilities of the remaining paths being critical considerably. On the other hand, this elimination reduced the computation duration to 107 seconds. Further path eliminations do not affect the probabilities until six paths remained. In this case, duration of analysis is 38 seconds and the deviations of probabilities considered with the first analysis are within $+3 \%$ of the initial probabilities. It is clear that the obtained probabilities are higher than the exact probabilities. In order to measure the effect of path elimination the analysis is continued by eliminating the sixth path, after this stage it is seen that the effect of path elimination is not ignorable.

\subsection{Test Problem 5}

Fifth test problem is a hypothetic test problem prepared for this study with 33 activities. Network diagram of the test problem is given in Figure 7.

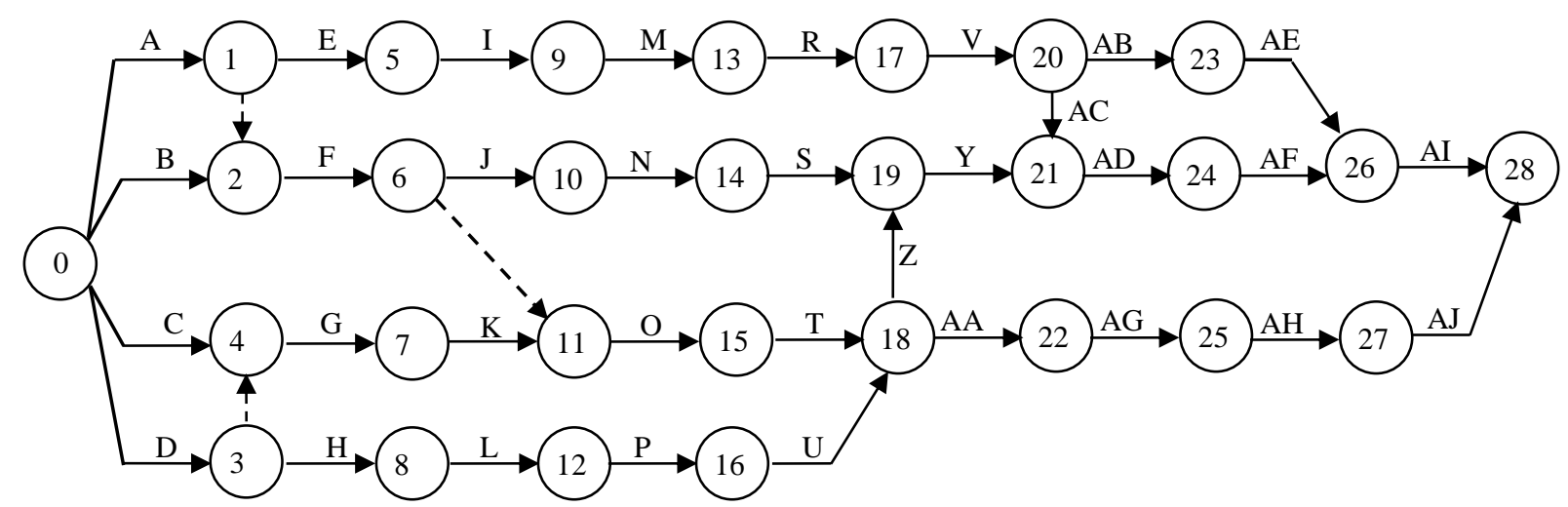

Figure 7. Activity on arrow diagram of the fifth problem

In the fifth sample problem float durations of the noncritical paths are short in contrast with the previous test problem. Therefore, the effects of the noncritical paths cannot be ignored. Table 19 presents optimistic, normal, and pessimistic durations of the activities. Expected duration, standard deviation and variance of the activity durations are computed and represented in the subsequent columns. Early and late event times of the starting and ending nodes of the activities are given in the following four columns and float durations of the activities are given in the last column of Table 19. Critical activities are represented in bold. Project duration and its uncertainty is estimated as $129 \pm 7.84$ days by PERT.

The fifth sample problem consists of 15 paths. Duration and variances of the paths are listed in Table 20. Determination of the paths becomes difficult and time consuming for large networks, since number of paths increases exponentially. Determination of the paths in the project requires automation for large networks. The automated path detection can be performed by network analysis algorithms [29]. However, implementation of network analysis algorithms precludes the simplicity of the PERT based methods.

Table 19. Activity durations and event times of the fifth case problem

\begin{tabular}{|l|l|l|l|l|l|l|l|l|l|l|l|}
\hline Activity & $\mathbf{a}$ & $\mathbf{m}$ & $\mathbf{b}$ & Dur. & Std. Dev & Var. & $\mathbf{E E T}_{\mathbf{i}}$ & $\mathbf{L E T}_{\mathbf{i}}$ & $\mathbf{E E T}_{\mathbf{j}}$ & $\mathbf{L E T}_{\mathbf{j}}$ & Total Float \\
\hline A & $\mathbf{7}$ & 9 & 11 & 9 & 1.25 & 1.56 & 0 & 0 & 9 & 13 & 4 \\
\hline B & 5 & 6 & 7 & 6 & 0.63 & 0.39 & 0 & 0 & 9 & 26 & 20 \\
\hline C & 4.5 & 5 & 5.5 & 5 & 0.31 & 0.10 & 0 & 0 & 5 & 8 & 3 \\
\hline $\boldsymbol{D}$ & $\mathbf{3 . 5}$ & $\mathbf{5}$ & $\mathbf{6 . 5}$ & $\mathbf{5}$ & $\mathbf{0 . 9 4}$ & $\mathbf{0 . 8 8}$ & $\mathbf{0}$ & $\mathbf{0}$ & $\mathbf{5}$ & $\mathbf{5}$ & 0 \\
\hline E & 8.5 & 11 & 13.5 & 11 & 1.56 & 2.44 & 9 & 13 & 20 & 24 & 4 \\
\hline
\end{tabular}




\begin{tabular}{|l|l|l|l|l|l|l|l|l|l|l|l|}
\hline F & 3.75 & 4 & 4.25 & 4 & 0.16 & 0.02 & 9 & 26 & 13 & 30 & 17 \\
\hline G & 7.75 & 9 & 10.25 & 9 & 0.78 & 0.61 & 5 & 8 & 14 & 17 & 3 \\
\hline $\boldsymbol{H}$ & $\mathbf{1 0}$ & $\mathbf{1 2}$ & $\mathbf{1 4}$ & $\mathbf{1 2}$ & $\mathbf{1 . 2 5}$ & $\mathbf{1 . 5 6}$ & $\mathbf{5}$ & $\mathbf{5}$ & $\mathbf{1 7}$ & $\mathbf{1 7}$ & 0 \\
\hline $\mathrm{I}$ & 12 & 13 & 14 & 13 & 0.63 & 0.39 & 20 & 24 & 33 & 37 & 4 \\
\hline $\mathrm{J}$ & 3 & 4 & 5 & 4 & 0.63 & 0.39 & 13 & 30 & 33 & 52 & 35 \\
\hline $\mathrm{K}$ & 10.5 & 13 & 15.5 & 13 & 1.56 & 2.44 & 14 & 17 & 27 & 30 & 3 \\
\hline $\boldsymbol{L}$ & $\mathbf{8}$ & $\mathbf{9}$ & $\mathbf{1 0}$ & $\mathbf{9}$ & $\mathbf{0 . 6 3}$ & $\mathbf{0 . 3 9}$ & $\mathbf{1 7}$ & $\mathbf{1 7}$ & $\mathbf{2 6}$ & $\mathbf{2 6}$ & 0 \\
\hline $\mathrm{M}$ & 10.5 & 12 & 13.5 & 12 & 0.94 & 0.88 & 33 & 37 & 45 & 49 & 4 \\
\hline $\mathrm{N}$ & 11 & 14 & 17 & 14 & 1.88 & 3.52 & 33 & 52 & 47 & 66 & 35 \\
\hline $\mathrm{O}$ & 14 & 17 & 20 & 17 & 1.88 & 3.52 & 27 & 30 & 44 & 47 & 3 \\
\hline $\boldsymbol{P}$ & $\mathbf{1 0}$ & $\mathbf{1 4}$ & $\mathbf{1 8}$ & $\mathbf{1 4}$ & $\mathbf{2 . 5 0}$ & $\mathbf{6 . 2 5}$ & $\mathbf{2 6}$ & $\mathbf{2 6}$ & $\mathbf{4 0}$ & $\mathbf{4 0}$ & 0 \\
\hline R & 14.5 & 17 & 19.5 & 17 & 1.56 & 2.44 & 45 & 49 & 62 & 66 & 4 \\
\hline $\mathrm{S}$ & 2 & 3 & 4 & 3 & 0.63 & 0.39 & 47 & 66 & 69 & 69 & 35 \\
\hline T & 3.5 & 4 & 4.5 & 4 & 0.31 & 0.10 & 44 & 47 & 51 & 51 & 3 \\
\hline $\boldsymbol{U}$ & $\mathbf{1 0}$ & $\mathbf{1 1}$ & $\mathbf{1 2}$ & $\mathbf{1 1}$ & $\mathbf{0 . 6 3}$ & $\mathbf{0 . 3 9}$ & $\mathbf{4 0}$ & $\mathbf{4 0}$ & $\mathbf{5 1}$ & $\mathbf{5 1}$ & 0 \\
\hline $\mathrm{V}$ & 9 & 10 & 11 & 10 & 0.63 & 0.39 & 62 & 66 & 72 & 76 & 4 \\
\hline $\boldsymbol{Y}$ & $\mathbf{1 5}$ & $\mathbf{2 0}$ & $\mathbf{2 5}$ & $\mathbf{2 0}$ & $\mathbf{3 . 1 3}$ & $\mathbf{9 . 7 7}$ & $\mathbf{6 9}$ & $\mathbf{6 9}$ & $\mathbf{8 9}$ & $\mathbf{8 9}$ & 0 \\
\hline $\boldsymbol{Z}$ & $\mathbf{1 2}$ & $\mathbf{1 8}$ & $\mathbf{2 4}$ & $\mathbf{1 8}$ & $\mathbf{3 . 7 5}$ & $\mathbf{1 4 . 0 6}$ & $\mathbf{5 1}$ & $\mathbf{5 1}$ & $\mathbf{6 9}$ & $\mathbf{6 9}$ & 0 \\
\hline AA & 11 & 19 & 27 & 19 & 5.00 & 25.00 & 51 & 51 & 70 & 88 & 18 \\
\hline AB & 8 & 13 & 18 & 13 & 3.13 & 9.77 & 72 & 76 & 85 & 102 & 17 \\
\hline AC & 7 & 13 & 19 & 13 & 3.75 & 14.06 & 72 & 76 & 89 & 89 & 4 \\
\hline $\boldsymbol{A D}$ & $\mathbf{1 2}$ & $\mathbf{2 0}$ & $\mathbf{2 8}$ & $\mathbf{2 0}$ & $\mathbf{5 . 0 0}$ & $\mathbf{2 5 . 0 0}$ & $\mathbf{8 9}$ & $\mathbf{8 9}$ & $\mathbf{1 0 9}$ & $\mathbf{1 0 9}$ & 0 \\
\hline AE & 9 & 19 & 29 & 19 & 6.25 & 39.06 & 85 & 102 & 121 & 121 & 17 \\
\hline $\boldsymbol{A F}$ & $\mathbf{1 0}$ & $\mathbf{1 2}$ & $\mathbf{1 4}$ & $\mathbf{1 2}$ & $\mathbf{1 . 2 5}$ & $\mathbf{1 . 5 6}$ & $\mathbf{1 0 9}$ & $\mathbf{1 0 9}$ & $\mathbf{1 2 1}$ & $\mathbf{1 2 1}$ & 0 \\
\hline AG & 11.5 & 16 & 20.5 & 16 & 2.81 & 7.91 & 70 & 88 & 86 & 104 & 18 \\
\hline AH & 11 & 15 & 19 & 15 & 2.50 & 6.25 & 86 & 104 & 101 & 119 & 18 \\
\hline $\boldsymbol{A I}$ & $\mathbf{6}$ & $\mathbf{8}$ & $\mathbf{1 0}$ & $\mathbf{8}$ & $\mathbf{1 . 2 5}$ & $\mathbf{1 . 5 6}$ & $\mathbf{1 2 1}$ & $\mathbf{1 2 1}$ & $\mathbf{1 2 9}$ & $\mathbf{1 2 9}$ & 0 \\
\hline AJ & 7.75 & 10 & 12.25 & 10 & 1.41 & 1.98 & 101 & $\mathbf{1 1 9}$ & 129 & $\mathbf{1 2 9}$ & 18 \\
\hline & & & & & & & & & & & \\
\hline
\end{tabular}

The network contains fifteen paths as shown in Table 20. Shortest four paths are eliminated and eleven paths are examined. The elimination is necessary since investigation of fifteen paths requires computation of 32767 events. Therefore eleven paths are investigated and 2047 events are examined.

Table 20. Paths of the fifth case problem

\begin{tabular}{|c|c|c|c|c|}
\hline No & Path & Duration & Variance & Std Dev \\
\hline 1 & D-H-L-P-U-Z-Y-AD-AF-AI & 129 & 61.43 & 7.84 \\
\hline 2 & C-G-K-O-T-Z-Y-AD-AF-AI & 126 & 58.72 & 7.66 \\
\hline 3 & D-G-K-O-T-Z-Y-AD-AF-AI & 126 & 59.50 & 7.71 \\
\hline 4 & A-E-I-M-R-V-AC-AD-AF-AI & 125 & 50.29 & 7.09 \\
\hline 5 & A-E-I-M-R-V-AB-AE-AI & 112 & 58.50 & 7.65 \\
\hline 6 & A-F-O-T-Z-Y-AD-AF-AI & 112 & 57.15 & 7.56 \\
\hline 7 & B-F-O-T-Z-Y-AD-AF-AI & 112 & 57.15 & 7.56 \\
\hline 8 & D-H-L-P-U-AA-AG-AH-AJ & 111 & 50.61 & 7.11 \\
\hline 9 & A-E-I-N-S-Y-AD-AF-AI & 110 & 46.19 & 6.80 \\
\hline 10 & C-G-K-O-T-AA-AG-AH-AJ & 108 & 47.90 & 6.92 \\
\hline 11 & D-G-K-O-T-AA-AG-AH-AJ & 108 & 48.68 & 6.98 \\
\hline 12 & $A-F-J-N-S-Y-A D-A F-A I$ & 94 & 43.77 & 6.62 \\
\hline 13 & $A-F-O-T-A A-A G-A H-A J$ & 94 & 46.34 & 6.81 \\
\hline 14 & $B-F-J-N-S-Y-A D-A F-A I$ & 91 & 42.60 & 6.53 \\
\hline 15 & $B-F-O-T-A A-A G-A H-A J$ & 91 & 45.17 & 6.72 \\
\hline
\end{tabular}


In Table 20, paths below line 11 do not have important probability of being longer than the longest path. Below line 11 the difference of the durations of the critical path and noncritical paths becomes $\pm 5 \sigma$. Therefore, first 11 paths are considered for the estimation of the duration and uncertainty of the duration of the project. Modified PERT estimates the project duration 131.645 \pm 6.275 days. Probabilities of the paths being critical path are computed by the proposed method and the results are presented in Table 21. First column represents the headings. First row identifies the number of analyzed paths, CT is the computation Time, and the remaining rows are the labels of the paths' number. Paths are sorted in descending order according to their durations and then their standard deviations. Therefore, probabilities of being critical path are obtained in descending order.

Analysis results given in Table 21 are conducted with numerical integration between 70 and 170 days with step size 0.2 day. Second column of Table 21 illustrates the analysis results conducted with eleven paths. In this case 2047 distinct events are examined. Computation time is 818 seconds and the probabilities of paths being critical path are given at the corresponding rows. Computation time is long for the first analysis because one path combination requires 500 numeric integration steps and this procedure is repeated 2047 times. If one path is ignored number of path combination becomes 1023 which halves the computational demand.

Table 21. Probabilities of being critical path of the fifth case study problem

\begin{tabular}{|l|l|l|l|l|l|l|l|l|l|l|l|}
\hline $\begin{array}{l}\text { No of } \\
\text { Paths }\end{array}$ & 11 & 10 & 9 & 8 & 7 & 6 & 5 & 4 & 3 & 2 & 1 \\
\hline CT & 818 & 336 & 224 & 96 & 60 & 20 & 11 & 5 & 2 & $<1$ & $<$ \\
\hline Path-1 & 0.3761 & 0.3763 & 0.3766 & 0.3772 & 0.3777 & 0.3787 & 0.3808 & 0.3831 & 0.4534 & 0.6110 & 1.00 \\
\hline Path-2 & 0.2232 & 0.2234 & 0.2236 & 0.2241 & 0.2244 & 0.2252 & 0.2268 & 0.2285 & 0.2792 & 0.3960 & \\
\hline Path-3 & 0.2219 & 0.2221 & 0.2223 & 0.2228 & 0.2232 & 0.2240 & 0.2255 & 0.2272 & 0.2781 & & \\
\hline Path-4 & 0.1694 & 0.1696 & 0.1698 & 0.1702 & 0.1706 & 0.1713 & 0.1728 & 0.1744 & & & \\
\hline Path-5 & 0.0072 & 0.0072 & 0.0072 & 0.0073 & 0.0073 & 0.0074 & 0.0075 & & & & \\
\hline Path-6 & 0.0068 & 0.0068 & 0.0068 & 0.0069 & 0.0069 & 0.0070 & & & & & \\
\hline Path-7 & 0.0035 & 0.0035 & 0.0035 & 0.0035 & 0.0036 & & & & & & \\
\hline Path-8 & 0.0018 & 0.0018 & 0.0018 & 0.0018 & & & & & & & \\
\hline Path-9 & 0.0023 & 0.0023 & 0.0023 & & & & & & & & \\
\hline Path-10 & 0.0010 & 0.0010 & & & & & & & & & \\
\hline Path-11 & 0.0009 & & & & & & & & & & \\
\hline
\end{tabular}

In the second analysis Path-11 is eliminated and remaining 10 paths are analyzed whose results are given in the third column. Computation time is measured as 336 seconds. Probabilities of the analysis with 11 paths and 10 paths are almost the same since the effect of the eliminated path is ignorable. However, computation time is reduced significantly. Paths with the least probability of being critical path are eliminated gradually. Elimination of a path causes a slight increase in the probability values of remaining paths. However, the effect of elimination is negligible until the elimination of Path-4. Detection of ineffective paths is important; this is because examination of an unnecessary path doubles the computational demand. Therefore, it is important to decide which paths to be kept in the analysis. The fourth analysis reveals that the paths whose durations are within $\pm 1 \sigma$ proximity with the shortest path have significant contribution. The researcher can adjust the number of examined paths by considering the sensitivity of the eliminated paths.

Computed probability values and computation time also depend on the range of numeric integration and step size. The effects of both parameters are monitored by a sensitivity analysis. The results of the analysis are given in Table 22. 
Table 22. Effects of step size and range on the accuracy of results

\begin{tabular}{|l|l|l|l|l|l|l|l|l|l|l|l|l|l|l|l|}
\hline A. ID & L. B. & U. B. & S. S. & T11 & T10 & T9 & T8 & T7 & T6 & T5 & T4 & T3 & T2 & T1 & Dev. \\
\hline 1 & 75 & 165 & 0.20 & 756 & 326 & 204 & 91 & 53 & 19 & 10 & 4 & 2 & $<1$ & $<1$ & 0.0000087 \\
\hline 2 & 80 & 160 & 0.20 & 702 & 320 & 152 & 75 & 35 & 18 & 8 & 4 & 2 & $<1$ & $<1$ & 0.0001218 \\
\hline 3 & 85 & 155 & 0.20 & 596 & 290 & 141 & 72 & 35 & 15 & 8 & 3 & 2 & $<1$ & $<1$ & 0.0014784 \\
\hline 4 & 90 & 154 & 0.20 & 546 & 265 & 123 & 55 & 31 & 15 & 6 & 3 & 1 & $<1$ & $<1$ & 0.0023245 \\
\hline 5 & 93 & 152 & 0.20 & 509 & 246 & 106 & 53 & 24 & 15 & 6 & 2 & 1 & $<1$ & $<1$ & 0.0037033 \\
\hline 6 & 93 & 152 & 0.25 & 389 & 203 & 105 & 44 & 21 & 10 & 5 & 2 & 1 & $<1$ & $<1$ & 0.0055193 \\
\hline 7 & 93 & 152 & 0.30 & 346 & 197 & 75 & 35 & 17 & 8 & 4 & 2 & 1 & $<1$ & $<1$ & 0.0071471 \\
\hline 8 & 93 & 152 & 0.40 & 270 & 122 & 68 & 28 & 13 & 6 & 3 & 1 & $<1$ & $<1$ & $<1$ & 0.0171688 \\
\hline 9 & 93 & 152 & 0.50 & 193 & 96 & 51 & 20 & 11 & 5 & 3 & 1 & $<1$ & $<1$ & $<1$ & 0.0278566 \\
\hline 10 & 93 & 152 & 0.75 & 150 & 66 & 32 & 16 & 7 & 3 & 2 & 1 & $<1$ & $<1$ & $<1$ & 0.0545079 \\
\hline 11 & 93 & 152 & 1.00 & 110 & 52 & 23 & 11 & 6 & 3 & 1 & $<1$ & $<1$ & $<1$ & $<1$ & 0.0796359 \\
\hline 12 & 93 & 152 & 1.50 & 75 & 32 & 19 & 9 & 3 & 2 & 1 & $<1$ & $<1$ & $<1$ & $<1$ & 0.1362414 \\
\hline 13 & 85 & 155 & 1.50 & 83 & 36 & 19 & 9 & 4 & 2 & 1 & $<1$ & $<1$ & $<1$ & $<1$ & 0.1323903 \\
\hline
\end{tabular}

Effects of step size and range are monitored by 13 analyses. Range is gradually reduced while the step size is increased regularly and both deviation of probability values and computation time is monitored. First column of Table 22 represents analysis ID. Second and third columns represent the lower and upper bounds of the numerical integration respectively. Fourth column represents step size of the numerical integration. Computation time in second is shown from sixth to seventeenth columns of the analysis of eleven to one path respectively. The heading $\mathrm{T}_{\mathrm{i}}$ represents that the probability analysis is conducted by considering $i$ paths. The last column represents the deviation from the exact solution. Deviation is obtained by the summation of the square of the differences between the exact values given in Table 21 and the obtained values by the corresponding parameters.

In analysis-1 range of numeric integration is reduced and computed probability values slightly deviate. In the second analysis the range is decreased further and the deviation increased. Amount of deviation is completely ignorable but the ratio of increment is very high when the deviation values between the first and second analysis are compared. Deviation increases with high ratio in the third analysis too but this trend is broken after the fourth analysis. Ignorance of a small region of numeric integration causes high increase in the error ratio even though the amount of contributing error is very small. Numerical integration range is contracted in the fourth and fifth analysis. The truncation error becomes significant when the range do not cover the $\pm 2 \sigma$ range of the paths. Saved computational time does not worth the loss in the accuracy after this range.

The effect of step size is examined between the sixth and the twelfth analyses. Step size has high effect on the accuracy and computation time. The analysis results show that selection of step size 0.4 day provides results with enough accuracy in reasonable computation time. If four paths are analyzed the computation take only 1 second.

Fourth case problem is also analyzed by MCS with 500 and 2500 sample sizes. Project duration and its uncertainty are estimated as $130.65 \pm 6.97$ and $130.87 \pm 6.88$ days respectively. When these estimations are compared with the Modified PERT results it is seen that iteration number of MCS should be increased since it underestimates the project duration if sample size is not adequate. For large networks, increasing the sample size is not practical because 2500 repetition is performed in 429 seconds in the average.

\section{DISCUSSION AND CONCLUSION}

In this study Modified PERT is improved and capability of computing the probability of a path being critical is added. Competence of the improvement is compared with MCS in terms of stability of the results and computational demand. Comparison is made by four hypothetical and one real projects. Sample problems contain small and simple network as well as large and complex networks. 
Analyses on the sample problems reveal that selection of step size has significant importance on the duration estimation with Modified PERT. Selection of large step size for the numeric integration causes underestimation of project duration while overestimation of uncertainty of the project duration.

Results of MCS also depend on the sample size. Selection of inadequate sample size causes underestimation of project duration. However, sample size has random effect on the uncertainty of project duration. Probability of paths being critical also changes when the sample size changes but there is not an apparent trend. In addition to this, small sample size increases the rounding errors of probability values.

Probability values compared by the improvement of the Modified PERT are similar to the results of MCS. In addition to this, sample problems are fabricated on purpose that in the first sample problem path- 3 and in the third sample problem path-1 would have almost 1 probability of being critical path. Obtained results are close to the expected probability values. Analysis result revealed that step size has important effect on the probability values. Selection of too high step size overestimates the probability values. The rate of overestimation decreases for the paths with high probability of being critical path.

Computation time of the probability computations of the paths being critical is significantly lower than MCS. Therefore, the improvement of Modified PERT is more suitable for the implementation at a stochastic optimization process. The proposed improvement will provide more accurate probability estimations with less computational demand.

Large networks have many paths and generation of all of the possible combinations manually would reduce the adoptability of the proposed improvement. Path combinations are generated by the developed cloning algorithm and distinct events are generated without any human intervention. This property is important for the utilization of the developed algorithm as the computations would be done without interruption.

Analyses on test problems show that if durations of the paths do not intersect within $\pm 1 \sigma$, then elimination of the shortest path would not have significant effect on the probability values of the remaining paths. Elimination of a path causes overestimation of the probability values of the remaining paths. On the other hand, elimination of an ineffective path halves the computational demand.

In this study, Modified PERT method is improved and it became capable of computing the probability of a path being critical path. The probability computation depends on the combinations of the paths of the network. In order to systematically execute the computations, relationship between the number of paths and distinct events are derived. A computer code is written on spreadsheet application and the improvement is tested. The results of the Modified PERT are compared by Monte Carlo Simulation. The comparison revealed that both methods provide similar results but the developed method is significantly faster than Monte Carlo Simulation.

Monte Carlo Simulation is the computationally most demanding method but the execution of the algorithm on a spreadsheet application is simpler than Modified PERT. Avoidance of analysis of the paths of the network makes the implementation of the MCS easier. The method is based on generation of random numbers, because of this there should be a proper random number generator. The correlations between the random numbers should be consistent with the probability density functions of the corresponding activities. This requirement increases the memory allocation of MCS. When the results of the analysis are examined, it can be concluded that Modified PERT method is more suitable method to estimate the variations of project duration. The computational saving is important through an iterative stochastic optimization process.

The sensitivity analysis provides important information on the truncation error. Range of numerical integration, step size and the number of analyzed paths can be selected effectively. Proposed range and step size parameters provide enough accuracy with short computation time. By using the proposed values for the step size and numeric integration range, stochastic optimization process can be conducted within reasonable time. 


\section{CONFLICTS OF INTEREST}

No conflict of interest was declared by the author.

\section{REFERENCES}

[1] Ahuja, H. N., and Nandakumar, V., "Simulation model to forecast project completion time", Journal of Construction Engineering and Management, 111(4): 325-342, (1985).

[2] Malcolm, D. G., Roseboom, J. H., Clark, C. E., and Fazar, W., "Application of a technique for research and development program evaluation", Operations research, 7(5): 646-669, (1959).

[3] Fulkerson, D. R., "Expected critical path lengths in PERT networks", Operations Research, 10(6): 808-817, (1962).

[4] Elmaghraby, S. E., "On the expected duration of PERT type networks", Management Science, 13(5): 299-306, (1967).

[5] Sculli, D., "The completion time of PERT networks", Journal of the Operational Research Society, 34(2): 155-158, (1983).

[6] Robillard, P., and Trahan, M., "Expected completion time in PERT networks", Operations Research, 24(1): 177-182, (1976).

[7] Robillard, P., and Trahan, M., "The completion time of PERT networks", Operations Research, 25(1): 15-29, (1977).

[8] Ang, A. H., Chaker, A. A., and Abdelnour, J., "Analysis of activity networks under uncertainty", Journal of the Engineering Mechanics Division, 101(4): 373-387, (1975).

[9] Taroun, A., "Towards a better modelling and assessment of construction risk: Insights from a literature review", International Journal of Project Management, 32(1): 101-115, (2014).

[10] Helton, J. C., "Uncertainty and sensitivity analysis techniques for use in performance assessment for radioactive waste disposal", Reliability Engineering \& System Safety, 42(2-3): 327-367, (1993).

[11] Cheah, C. Y., and Liu, J., "Valuing governmental support in infrastructure projects as real options using Monte Carlo simulation", Construction Management and Economics, 24(5): 545-554, (2006).

[12] Khamooshi, H., and Cioffi, D. F., "Uncertainty in task duration and cost estimates: Fusion of probabilistic forecasts and deterministic scheduling", Journal of Construction Engineering and Management, 139(5): 488-497, (2012).

[13] Tao, L., Wu, D., Liu, S., and Lambert, J. H., "Schedule risk analysis for new-product development: The GERT method extended by a characteristic function", Reliability Engineering \& System Safety, 167: 464-473, (2017).

[14] Van Slyke, R. M., "Letter to the editor-monte carlo methods and the pert problem", Operations Research, 11(5): 839-860, (1963).

[15] Burt, J., and Garman, M., "Monte Carlo techniques for stochastic PERT network analysis", INFOR: Information Systems and Operational Research, 9(3): 248-262, (1971).

[16] Sigal, C. E., Pritsker, A. A. B., and Solberg, J. J., "The use of cutsets in Monte Carlo analysis of stochastic networks", Mathematics and Computers in Simulation, 21(4): 376-384, (1979). 
[17] Dodin, B. M., and Elmaghraby, S. E., "Approximating the criticality indices of the activities in PERT networks", Management Science, 31(2): 207-223, (1985).

[18] Choudhry, R. M., Aslam, M. A., Hinze, J. W., and Arain, F. M., "Cost and schedule risk analysis of bridge construction in Pakistan: Establishing risk guidelines", Journal of Construction Engineering and Management, 140(7): 04014020, (2014).

[19] Dawood, N., "Estimating project and activity duration: a risk management approach using network analysis", Construction Management \& Economics, 16(1): 41-48, (1998).

[20] Lee, D. E., "Probability of project completion using stochastic project scheduling simulation", Journal of Construction Engineering and Management, 131(3): 310-318, (2005).

[21] Lee, D. E., and Arditi, D., "Automated statistical analysis in stochastic project scheduling simulation", Journal of Construction Engineering and Management, 132(3): 268-277, (2006).

[22] Jevtic, V., Dobrilovic, D., Stojanov, J., and Stojanov, Z., "Project Duration Assessment Model Based on Modified Shortest Path Algorithm and Superposition", 13 ${ }^{\text {th }}$ IEEE International Symposium on Symbolic and Numeric Algorithms for Scientific Computing (SYNASC), 87-90, (2011).

[23] Guo, Q. L., Maher, M., and Wamuziri, S., "Risk analysis in construction networks using a modified stochastic assignment model", Civil Engineering Systems, 18(3): 215-241, (2001).

[24] Diaz, C. F., and Hadipriono, F. C., "Nondeterministic networking methods", Journal of Construction Engineering and Management, 119(1): 40-57, (1993).

[25] Al-Sadek, O., and Carmichael, D. G., "On simulation in planning networks", Civil Engineering Systems, 9(1): 59-68, (1992).

[26] MacCrimmon, K. R., and Ryavec, C. A., "An analytical study of the PERT assumptions", Operations Research, 12(1): 16-37, (1964).

[27] Moder, J. J., Phillips C. R., and Davis E. W., Project management with CPM, PERT and precedence diagramming $3^{\text {rd }}$ Edition, Van Nostrand Reinhold Company, New York (1983).

[28] United States Air Force, "PERT-time system description manual", US Air Force Systems Command, (1963).

[29] Bettemir, Ö. H., and Birgönül, M. T., "Network analysis algorithm for the solution of discrete timecost trade-off problem", KSCE Journal of Civil Engineering, 21(4): 1047-1058, (2017). 


\section{APPENDIX}

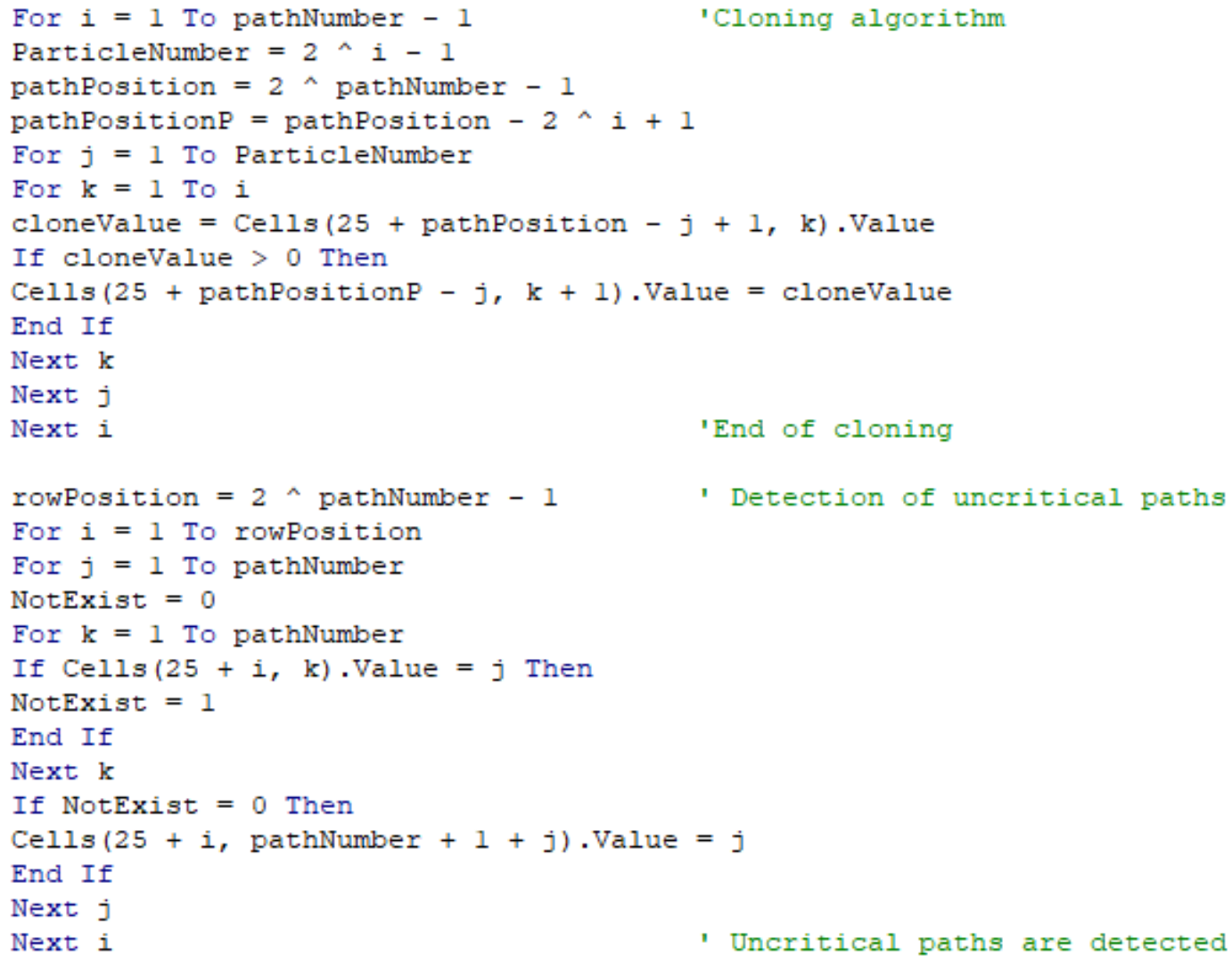

Figure A1. Visual Basic code of the cloning algorithm 